\title{
SOCIO-DEMOGRAPHIC VARIABLES AND UTILIZATION OF PRESCRIBED EYEGLASSES AMONG STAFF OF TERTIARY INSTITUTIONS IN AKWA IBOM STATE, NIGERIA
}

\author{
Asuquo I. Enyim \\ Department of Physical \& Health Education, Faculty of Education. University of Uyo, \\ Akwa Ibom State, Nigeria
}

\section{ABSTRACT}

The study was conducted to determine the influence of socio-demographic variables on utilization of prescribed eyeglasses among staff of tertiary institutions in Akwa Ibom State. Specifically, the influence of age, gender, level of education, profession, years of service, income status, attitudes, beliefs and age of onset (of vision impairment) were examined on the utilization of eyeglasses. Nine research questions and nine hypotheses formulated to guide the study. Descriptive survey design was adopted for the study. The population for the study comprised only staff that used prescribed eyeglasses out of the 4,498 senior staff of the nine approved tertiary institutions in the state. A sample size of 900 was selected through stratified purposive sampling. A researcher developed instrument titled "Socio-demographic Variables and Utilization of Prescribed Eyeglasses Questionnaire (SVUPEQ)" with reliability index of .83 was used for data collection. A total of $882(98 \%)$ of the 900 distributed copies of questionnaire were retrieved. Data were analyzed using Statistical Package for Social Science (SPSS) software. Mean and Standard deviation were used to answer the research question; while Analysis of Variance and Independent $t$-test were used for test of hypotheses at .05 probability level of significance. Findings revealed that seven out of the nine examined variables exerted statistical significant influence on utilization of prescribed eyeglasses. It was therefore concluded that Socio-demographic Variables (level of education, profession, years of service, income status, attitudes, beliefs and age of onset) have statistical significant influence on utilization of prescribed eyeglasses among staff of tertiary institutions in Akwa Ibom State, Nigeria. Intensive vision-health education campaign was recommended to enhance improvement in the rate of utilization of prescribed eyeglasses.' Keywords: PRESCRIBED EYEGLASSES, SOCIO-DEMOGRAPHIC VARIABLES

DOI: $10.7176 / \mathrm{JEP} / 10-7-10$

Publication date:March $31^{\text {st }} 2019$

\section{Background of the Study}

The eye is a very important organ for sight. No man can function effectively in any occupation without healthy eyes with good vision. Good visual ability is therefore an indispensable requirement in most occupations, including pastimes and sports. The most common vision problems that affect people of all age-groups are the refractive errors. Such refractive errors occur when the shape of the eyeball is either too long or too short to prevent light rays that enter the eye from focusing on the retina. Vision Spring (2007) acknowledged that vision impairment due to refractive error is a very serious health problem because it is always associated with severe physical, emotional, educational, socio-economic and public-safety implications. Therefore, vision impairment from uncorrected refractive errors has tremendous impact on people's quality of life, limiting the educational and employment opportunities of people as well as reducing the productivity of workers.

Vision impairment due to refractive errors affects many categories of workers, especially those whose duties involve much writings and reading of printed materials (George, 2012). A greater percentage of clerical staff and other office-workers are affected because of their routine duty requirements. Workers that make use of laptops and other computers in their workplaces are also affected, including the drivers, technicians and certain farmers that deal with tiny seeds, such as cotton farmers. Teachers and students of all institutions of learning are also affected because no meaningful academic programme can take place successfully without healthy eyes with good vision (Calonge, 2013).

Ebeigbe, Kior and Okafor (2013) asserted that every minor reduction in the visual status of the eye due to refractive errors is usually associated with increased risk of physical, social and emotional disturbances, especially in people of fifty years of age and above. These authors further explained that refractive errors can simply be diagnosed and treated with the aid of optical corrective measures, such as the use of prescribed eyeglasses, contact lenses and refractive surgeries, specifying the utilization of prescribed eyeglasses as the best 
and most accessible treatment option. But despite these corrective approaches, an estimated 670 million people with correctable refractive errors across the globe have no access to the prescribed eyeglasses (Resnikoff, Pascolini, Marriotti and Pokharel, 2008). Dandona and Dandona (2006a) submitted that the eyeglasses have not been adequately utilized in many parts of the world, specially the developing countries.

The World Health Organization (WHO) (2008) reported that over 2.3billion people all over the world suffer from avoidable vision impairment due to refractive errors. The same report indicated that the highest percentages of all types of refractive errors are found in African sub-region and other developing countries of the world. This therefore confirmed the essential need for adequate utilization of eyeglasses for treatment and timely correction of all types of refractive errors to reduce the number of avoidable blindness in the world. The inadequate and poor utilization of eyeglasses has been considered as public health problem in most developing countries of the world. Holden, Fricke and Naidoo (2008) submitted that any modest amount of correction of refractive errors with eyeglasses can significantly improve visual functioning with attendant improvement in one's quality of life and duty performances. The utilization of prescribed eyeglasses is highly recommended because other treatment options for correction of refractive errors namely; the use of prescribed contact lenses and refractive surgeries are much less accessible.

The utilization of health services/healthcare products refers to the extent of which people in any given population make use of any particular healthcare service or healthcare-product within a specified period of time. Morse (2013) defined healthcare utilization as the number of people that obtained any particular healthcare service or services over a period of time; especially when the people are eligible for such services. The utilization of healthcare services can also be expressed as the proportion of people in need of a particular service and those who actually obtained and make use of such service or services in a given period, usually one year. The inadequate utilization of prescribed eyeglasses in any population refers to insufficient rate of usage of prescribed eyeglasses in such population compared to the number of people with viable refractive errors.

Adam and Awunor (2014) opined that adequate utilization of healthcare services or healthcare products has the capacity to improve the health status of any population. The authors however, reiterated that an availability of any aspect of healthcare services does not guarantee adequate utilization of such service because several factors such as the socio-demographic characteristic of the people and their religious beliefs can interfere with their health seeking behaviours. Oladipo (2014) asserted that socio-demographic variables are the major predisposing factors that influence the utilization of healthcare services, adding that such influences may be favourable, inclined or susceptible.

Furthermore Oladipo (2014) listed socio-demographic variables to include age, sex, religion, occupation, education, family size, ethnicity, culture, attitudes, beliefs and health education. Specifically, the sociodemographic variables to be considered in the present study include age, gender, level of education and profession. Others are years of service, income status, attitude, beliefs and the age of onset of respondents' vision impairment. Age of onset is a medical term referring to the age at which an individual acquires, develops or first experiences of a condition or symptom of a disease or disorder (Jones, 2013). The age of onset in the present study refers to the period of time or the actual year that vision impairment due refractive errors had first manifested, including when such impairment became very serious to make its victim (client) to seek an eye-specialist attention to obtain and start using prescribed eyeglasses.

Eye care services on the other hand refer to the provision of all affordable eye-health and vision-health services to meets the patients' needs in a comprehensive and competent manner. The eye care professionals that are responsible for the provision of primary eye care services, including the provision of prescribed eyeglasses include ophthalmologist, optometrist, ophthalmic Nurses as well as opticians. Dandona and Dandona (2006b) asserted that inadequate utilization of prescribed eyeglasses has persisted in most developing countries of the world, especially the sub-Saharan African nations. At individuals' level, any person that obtained the prescribed eyeglasses, but always forget the spectacles at home or in the car or bag cannot be said to have made adequate utilization of such eyeglasses

The World Health Organization (2013) identified "refractive error" as a very common eye disorder, and listed four most common refractive errors as myopia, hyperopia, astigmatism and presbyopia. The refractive errors result from inability of the eye to focus images properly on the retina, characterized by blurring of both near and distance vision. The prescribed eyeglasses are frame-bearing transparent lenses that are worn in-front of the eyes for treatment and correction of refractive errors and other ocular problems, such as aphakia and strabismus. The International Agency for Prevention of Blindness (2006) asserted that eyeglasses remain as ideal solution to all 
refractive errors. Such eyeglasses are said to be prescribed when ordered by eye care specialists, as ophthalmologists, optometrists or ophthalmic opticians after due ophthalmic tests and examinations.

The "staff of tertiary institutions in Akwa Ibom State"' in the present study refers to the various ranks of academic staff and administrative/technical officers: "the senior staff" of the nine approved public and private tertiary institutions by the National Universities Commission (NUC) and the National Board for Technical Education (NBTE) respectively in the state. They include the senior staff of: University of Uyo, Akwa Ibom State University, Ikot Akpaden; Obong University, Obong Ntak; and those of Ritman University, Ikot Ekpene. Others comprise the senior staff of Federal Polytechnic, Ukana; Akwa Ibom State Polytechnic, Ikot Osurua; Akwa Ibom State College of Education, Afaha-Nsit as well as those of Maritime Academy, Oron and the senior staff of Heritage Polytechnic, Ikot Udota in Eket Local Government of Akwa Ibom State.

\section{Statement of the Problem}

The utilization of prescribed eyeglasses is considered as the best, most accessible and acceptable treatment option for correction of vision impairment due to refractive errors in all parts of the world. However, the prescribed eyeglasses have not been adequately utilized in most developing countries, including Nigeria, despite realistic progress and advancement in ophthalmic sciences and modern eye-care services (Adeoti, 2009). An example of poor rate of utilization of prescribed eyeglasses was particularly observed in Akwa Ibom State by a study which indicated that less than 10 percent of secondary school students with viable refractive errors were found to have obtained and made use of prescribed eyeglasses for treatment and correction of their vision problems (Megbalayin, 2013). The inadequate utilization may not be unconnected with lack of appropriate knowledge of the benefits that are derived from optimum utilization of the prescribed eyeglasses. Wrong beliefs, ignorance, poverty and the high dispensing cost of the eyeglasses may constitute some of the major factors responsible for the poor and inadequate utilization of the prescribed eyeglasses.

The persistent low and inadequate utilization of prescribed eyeglasses in the developing countries was one of the major reasons why the World Health Organization constituted "Vision 2020" otherwise known as the "Right to Sight Programme" in 1999; with one outstanding mission to eliminate all the major forms of preventable and treatable causes of low vision and blindness, including the refractive errors. The Vision 2020 alongside the International Agency for Prevention of Blindness (IAPB) over the years has continued to call for expansion of eye-care services to reduce all forms of preventable blindness. However, studies on prescribed eyeglasses utilization in Nigeria over the past ten years have continued to show very low rate of utilization despite the high prevalence rate of refractive errors in the country (Adeoti, 2009; Megbalayin, 2013).

The present study became necessary because most of the previous studies to the best of the researcher's knowledge were conducted on "prevalence of refractive errors and utilization of eyeglasses" without due considerations to personal and social characteristics of the people that needed to have obtained such eyeglasses. The researcher from his personal encounter with some staff of tertiary institutions over the past five years had also observed certain eye-health behaviours and eyeglasses utilization attitudes that motivated his interest to use the staff of tertiary institutions for the study. It is against this backdrop that researcher set out to investigate the influence of socio-demographic variables on utilization of prescribed eyeglasses among staff of tertiary institutions in Akwa Ibom State, Nigeria.

\section{Purpose of the Study}

The purpose of this study was to investigate the influence of socio-demographic variables on utilization of prescribed eyeglasses among staff of tertiary institutions in Akwa Ibom State, Nigeria. Specifically, the study aimed to achieve the following nine objectives:

1. Determine the influence of age on utilization of prescribed eyeglasses among staff of tertiary institutions in Akwa Ibom State, Nigeria.

2. Examine the influence of gender on utilization of prescribed eyeglasses among staff of tertiary institutions in Akwa Ibom State, Nigeria.

3. Ascertain the influence of level of education on utilization of prescribed eyeglasses among staff of tertiary institutions in Akwa Ibom State, Nigeria.

4. Determine the influence of profession on utilization of prescribed eyeglasses among staff of tertiary institutions in Akwa Ibom State, Nigeria.

5. Determine the influence of years of service (working years) on utilization of prescribed eyeglasses among staff of tertiary institutions in Akwa Ibom State, Nigeria. 
6. Examine the influence of income status (monthly earnings) on utilization of prescribed eyeglasses among staff of tertiary institutions in Akwa Ibom State, Nigeria.

7. Examine the influence of age of onset (of vision impairment) on utilization of prescribed eyeglasses among staff of tertiary institutions in Akwa Ibom State, Nigeria.

8. Ascertain the influence of staff's attitudes toward the utilization of prescribed eyeglasses in tertiary institutions in Akwa Ibom State, Nigeria.

9. Determine the influence of beliefs on utilization of prescribed eyeglasses among staff of tertiary institutions in Akwa Ibom State, Nigeria.

\section{Research Questions}

The following nine research questions were generated from specific objectives to guide the study:

1. How does age influence the utilization of prescribed eyeglasses among staff of tertiary institutions in Akwa Ibom State, Nigeria?

2. How does gender influence the utilization of prescribed eyeglasses among staff of tertiary institutions in Akwa Ibom State, Nigeria?

3. How does level of education influence the utilization of prescribed eyeglasses among staff of tertiary institutions in Akwa Ibom State, Nigeria?

4. How does profession influence the utilization of prescribed eyeglasses among staff of tertiary institutions in Akwa Ibom State, Nigeria?

5. How do years of service (working years) influence the utilization of prescribed eyeglasses among staff of tertiary institutions in Akwa Ibom State, Nigeria?

6. How does income status (monthly earnings) influence the utilization of prescribed eyeglasses among staff of tertiary institutions in Akwa Ibom State, Nigeria?

7. How does age of onset (of vision impairment) influence the utilization of prescribed eyeglasses among staff of tertiary institutions in Akwa Ibom State, Nigeria?

8. How do staff's attitudes toward prescribed eyeglasses influence their utilization in tertiary institutions in Akwa Ibom State, Nigeria?

9. How do beliefs influence the utilization of prescribed eyeglasses among staff of tertiary institutions in Akwa Ibom State, Nigeria?

\section{Research Hypotheses}

The following nine null hypotheses were formulated from specific objectives to guide the study. They were tested at .05 probability level of significance.

1. Age has no significant influence on the utilization of prescribed eyeglasses among staff of tertiary institutions in Akwa Ibom State, Nigeria.

2. Gender has no significant influence on the utilization of prescribed eyeglasses among staff of tertiary institutions in Akwa Ibom State, Nigeria.

3. Level of education has no significant influence on the utilization of prescribed eyeglasses among staff of tertiary institutions in Akwa Ibom State, Nigeria.

4. Profession has no significant influence on the utilization of prescribed eyeglasses among staff of tertiary institutions in Akwa Ibom State, Nigeria.

5. Years of service (working years) have no significant influence on the utilization of prescribed eyeglasses among staff of tertiary institutions in Akwa Ibom State, Nigeria.

6. Income status (monthly earnings) has no significant influence on the utilization of prescribed eyeglasses among staff of tertiary institutions in Akwa Ibom State, Nigeria.

7. Age of onset (of vision impairment) has no significant influence on the utilization of prescribed eyeglasses among staff of tertiary institutions in Akwa Ibom State, Nigeria.

8. Attitudes of staff toward prescribed eyeglasses have no significant influence on their utilization in tertiary institution in Akwa Ibom State, Nigeria.

9. Beliefs have no significant influence on the utilization of prescribed eyeglasses among staff of tertiary institutions in Akwa Ibom State, Nigeria.

\section{Delimitations}

The study was delimitated to the influence of socio-demographic variables on utilization of prescribed eyeglasses among staff of tertiary institutions in Akwa Ibom State. It was delimitated to the senior staff of the approved tertiary educational institutions by NUC and NBTE respectively; and not those from the non-approved tertiary institutions. 


\section{Literature Review}

The review of related literature on socio-demographic variables and utilization of prescribed eyeglasses among staff of tertiary institutions in Akwa Ibom State covered the theoretical framework conceptual framework and empirical framework as well as summary of the literature review.

\section{Research Methods}

The methods used by the researcher to investigate the influence of socio-demographic variables on utilization of prescribed eyeglasses among staff of tertiary institutions in Akwa Ibom State included the following:

\section{Research Design}

A descriptive survey design was adopted for the study. The researcher considered the descriptive survey as the most appropriate design for the study because it enhanced collection of first hand information from a large population of the respondents in their natural settings (which were the respective tertiary institutions where the respondents are working.

\section{Area of the Study}

The study was carried out in Akwa Ibom State, one of the thirty six states of the Federal Republic of Nigeria. Akwa Ibom State is located in the South-South geopolitical zone, with a land mass of 7,081 square kilometers. The state is bounded on the East by Cross River State on the West by Abia and River States, on the North by Abia State and on the South by the Atlantic Ocean, which span a distance of $129 \mathrm{~km}$ from Ikot Abasi to Oron. Akwa Ibom State is situated in the North of the Equator, and lies between latitudes $4^{0} 33^{1}$ and $5^{0} 33^{1}$ North and longitudes $7^{0} 35^{1}$ and $8^{0} 25^{1}$ East (Akwa Ibom State Diary, 2015). The National Population Commission's Estimate (2013) indicated Akwa Ibom State as being thickly populated with 3.9 million people.

\section{Population for the Study}

The population for the study comprised all senior staff of the nine approved tertiary institutions in the state, but specifically those that use prescribed eyeglasses. The population of the entire senior staff across the nine tertiary institutions was about 4,498 as at January, 2016 (Akpan, 2015; University of Uyo, 2015; Utiam, 2015; Elensi, 2016; Essien, 2016). The respondents that used prescribed eyeglasses were specifically selected from the entire senior staff's population across the nine tertiary institutions because there was no provision data available.

\section{Sample and Sampling Technique}

A sample size of 900 (20 percent of the senior staff population across the nine approved tertiary educational institutions in the state) but specifically those that used prescribed eyeglasses were selected for the study through stratified purposive sampling. Ndiyo (2005) recommended that a sample size should statistically be made up of 15 to 30 percent of the population of study; explaining that a smaller population can be studied entirely as sample. Therefore, the sample size of 900 (20 percent of the senior staff's population) used in the study was considered appropriate as recommended.

Proportionate stratified sampling using a sample fraction of $1 / 5$ was applied to select the 900 respondents for the study across the nine institutions. Each of the nine tertiary institutions in the state served as a stratum for the study to allow proportional distribution of the respondent based on the senior staff population of each institution. Within each of the tertiary institutions, faculties were selected through simple random technique which permitted equal chances of participation to staff of different faculties of the respective institutions; while opportunistic sampling was used to select senior staff that used eyeglasses as participants for the study based on the staff's availability in the respective institutions during the days of questionnaire administration and the willingness of the staff to participate in the study.

\section{Instrument for Data Collection}

A researcher developed instrument, "Socio-demographic Variable and Utilization of Prescribed Eyeglasses Questionnaire (SVUPEQ), made up of seventy close ended items was used as the only instrument to elicit information for the study. The questionnaires were administered specifically on senior staff that used prescribed eyeglasses across the nine approved tertiary educational institutions in the state. 


\section{Validation of the Instrument}

The face validation of the instrument (SVUPEQ) was accomplished by submitting the draft questionnaire to three experts in the Faculty of Education; two in the Department of Physical and Health Education, one expert on Measurement and Evaluation for necessary correction. The experts scrutinized and matched all items with the research questions and hypotheses to ascertain the validity of the instrument. They modified the instrument by removing all ambiguous items; thereby reducing the number of items from eighty to seventy. This was done to make sure that the instrument measured what it intended to measure. The final copy of the instrument was produced based on the approval and recommendations of the experts.

\section{Reliability of the Instrument}

The reliability of the instrument (SVUPEQ) was established by administering the questionnaire to a group of forty staff of a tertiary institution that did not take part in the study; but who was assumed to have equivalent characteristics with the respondents that participated in the study. Therefore, forty copies of questionnaires were administered on forty staff of the University of Calabar in the same South-South Geo-political Zone because they were assumed to have equivalent socio-demographic and cultural characteristics with those that participate in the study. Data from the pre-test of the instrument were analyzed using Cronbach-alpha statistics to determine its reliability; and same yielded a reliability coefficient of .83 which indicated that the instrument was reliable.

\section{Methods of Data Analysis}

Statistical Package for Social Sciences (SPSS) software was used to analyze the generated data. Mean, standard deviation and mean of items were used to answer the research questions; while Independent t-test and one-way analysis of variance (ANOVA) were used for the test of hypotheses. All hypotheses were tested at .05 probability level of significance.

\section{Decision Rules}

(a) To answer each of the nine research questions, mean of items was employed for decision to be taken on whether the respondents were strongly agreed, agreed, disagreed or strongly disagreed. The mean of items was obtained by dividing the mean by the number of items of the dependent variable. When a value was obtained, the upper limit of the numbers 1, 2, 3 and 4 which were the scores for strongly disagreed, disagreed, agreed and strongly agreed were used in taking decision on the responses of the respondents. For instance, the mean of items of 2.8 which is above the upper limit of 2 and below the upper limit of 3 implied that the respondents were agreeing on the influence of the variable on the utilization of prescribed eyeglasses.

(b) To determine whether a respondent has positive or negative attitude toward the utilization of prescribed eyeglasses in the 8th research question, 10 points were used because attitude as an independent variable had 5 items. The "True", "False" and the "Indifference" responses of these items were scored 3, 2 and 1 point respectively; resulting to an average of 2 points per each item. Thus, the 10 points were derived by multiplying the 2 points by the number of items $(2 \times 5=10)$. Consequently, any respondent who scored below 10 points was regarded as having negative attitude while those who scored 10 points and above were regarded as having positive attitudes. The same principle was also used to separate respondents having negative and positive beliefs in answering the 9 th research question.

(c) In the test of hypotheses, whenever the calculated value (t-cal or F-cal) was greater than the critical value (tcritical or F-crit.) the null hypothesis was rejected; while the null hypotheses were accepted whenever the calculated values were less than the critical values.

(d) One-way Analysis of Variance was used whenever the variables were up to three or more while the Independent t-test was adopted whenever the items of the variables were two. 


\section{Results and Discussion of Findings}

The results of data analysis carried out on the data that were generated from the study were as followed. A total of 900 copies of questionnaires were distributed to 900 respondents across the nine approved tertiary institutions in the state, of which $882(98 \%)$ were successfully retrieved. The results of the analyses of the data are hereby presented as well as the discussion of findings. The presentations are in line with the nine research questions and nine hypotheses that were formulated to guide the study in the following ways:

\section{Presentation of the Results}

\section{(A)Answering of the Research Questions}

\section{Research Question 1:}

How does age influence the utilization of prescribed eyeglasses among staff of tertiary institutions in Akwa Ibom State, Nigeria?

Table 1: Mean, Standard Deviation, and Mean of items of Scores of Utilization of Prescribed Eyeglasses among Staff of Tertiary Institutions in Akwa Ibom State of Nigeria, based on Age $(\mathbf{N}=\mathbf{8 8 2})$

\section{Group Statistics}

\begin{tabular}{l|c|c|c|c|c}
\hline Age of Staff & $\mathbf{N}$ & $\begin{array}{c}\text { Mean } \\
(\bar{x})\end{array}$ & $\begin{array}{c}\text { Standard } \\
\text { Deviation }\end{array}$ & $\begin{array}{l}\text { Mean of } \\
\text { Items }\end{array}$ & Remarks \\
\hline 26 to 40 years & 144 & 150.63 & 8.85 & 2.84 & Agreed \\
41 to 55 years & 545 & 150.43 & 9.88 & 2.84 & Agreed \\
56 years and above & 193 & 151.18 & 8.29 & 2.85 & Agreed \\
\hline
\end{tabular}

The results in Table 1 show the mean, standard deviation and mean of items as well as the remarks on the influence of age on the utilization of prescribed eyeglasses among staff of tertiary institutions in Akwa State, Nigeria. The 144 respondents of 26 to 40years had mean of 150.63 and a standard deviation of $8.85,545$ respondents of 41 to 55 years had mean of 150.43 and a standard deviation of 9.88; while the remaining 193 respondents of 56years and above had 151.18 and 8.29 as their mean and standard deviation respectively. Table 1 also reveals the mean of items of the respondents of 26 to 40years, 41 to 55years and those of 56years and above as 2.84, 2.84 and 2.85 respectively. The mean of items of $2.84,2.84$ and 2.85 are above the upper limit of 2 and below the upper limit of 3 which in the 4 points scale of strongly agreed, agreed, disagreed and strongly disagreed are on the "agreed", level. Since three means of items are on the same level of agreement, it implies that the respondents of the three age-groups were agreeing on the influence of age on the utilization of prescribed eyeglasses. This therefore suggested that age has positive influence on the utilization of prescribed eyeglasses among staff of tertiary institutions in Akwa Ibom State, Nigeria.

\section{Research Question 2:}

How does gender influence the utilization of prescribed eyeglasses among staff of tertiary institutions in Akwa Ibom State, Nigeria?

Table 2: Mean, Standard Deviation and Mean of items of Scores of Utilization of Prescribed Eyeglasses among Staff of Tertiary Institutions in Akwa Ibom State of Nigeria, based on Gender

$(\mathbf{N}=\mathbf{8 8 2})$

\begin{tabular}{l|c|c|c|l|l}
\hline Gender & $\mathbf{N}$ & $\begin{array}{c}\text { Mean } \\
(\bar{x})\end{array}$ & $\begin{array}{l}\text { Standard } \\
\text { Deviation }\end{array}$ & $\begin{array}{l}\text { Mean of } \\
\text { Items }\end{array}$ & Remarks \\
\hline Female & 501 & 151.07 & 8.81 & 2.85 & Agreed \\
Male & 381 & 150.05 & 10.07 & 2.83 & Agreed
\end{tabular}


The result in Table 2 show the mean, standard deviation and mean of items of scores of the utilization of prescribed eyeglasses among staff of tertiary institutions in Akwa Ibom State based on gender. The mean of 501 female respondents was 151.07 and a standard deviation of 8.81; while that of 381 male respondents was 150.05 with a standard deviation of 10.07. These mean of item of female and male respondents recorded 2.85 and 2.83 respectively. The means of item of 2.85 and 283 are above the upper limit 2 and below the upper limit of 3 which in the 4 point scale of strongly agreed, agreed, disagreed and strongly disagreed are on the " agreed"' level. Since the two means of items are on the same level of agreement, it implies that the two groups of respondents were agreeing on the influence of gender on the utilization of prescribed eyeglasses. This therefore suggested that gender has positive influence on the utilization of prescribed eyeglasses among staff of tertiary institutions in Akwa Ibom State, Nigeria.

Research Question 3:

How does level of education influence the utilization of prescribed eyeglasses among staff of tertiary institutions in Akwa Ibom State, Nigeria?

Table3: Mean, Standard Deviation and Mean of items of Scores of Utilization of Prescribed Eyeglasses among staff of Tertiary Institutions in Akwa Ibom State of Nigeria, based on Level of Education( $\mathbf{N}=\mathbf{8 8 2})$

Group Statistics

\begin{tabular}{l|c|c|c|c|c}
\hline Level of Education & N & $\begin{array}{c}\text { Mean } \\
(\bar{x})\end{array}$ & $\begin{array}{l}\text { Standard } \\
\text { Deviation }\end{array}$ & $\begin{array}{l}\text { Mean } \\
\text { of Item }\end{array}$ & Remarks \\
\hline Diploma Level & 177 & 149.06 & 9.94 & 2.81 & Agreed \\
HND/First Degree Level & 321 & 150.06 & 9.72 & 2.83 & Agreed \\
Master Degree Level & 292 & 151.99 & 8.28 & 2.87 & Agreed \\
Doctorate Degree Level & 58 & 151.50 & 9.35 & 2.86 & Agreed \\
Professorial Attainment Level & 34 & 150.91 & 10.86 & 2.85 & Agreed \\
\hline
\end{tabular}

The results in Table 3 show the mean, standard deviation and mean of items of scores of the utilization of prescribed eyeglasses among staff of tertiary institutions in Akwa Ibom State based on level of education. The 292 respondents with master degree had the highest mean, 151.99 and a standard deviation of 8.28; followed by 58 respondents with doctorate degree who had mean of 151.50 and standard deviation of 9.35 . The respondents with Diploma as their highest level of educational attainment had the lowest mean of 149.06 and a standard deviation of 9.94. The 321 respondents with HND/First degree had mean of 150.06 and standard deviation of 9.72 while the 34 respondents who were professors had mean of 150.91 with a standard deviation of 10.86 . Table 3 also reveals that the five groups of respondents with diploma, HND/First degree, master degree, doctorate degree and professorial attainments had means of items of 2.81, 2.83, 2.87, 2.86 and 2.85 respectively. The mean of items of these five groups of respondents $(2.81,2.83,2.87,2.86$ and 2.85) are above the upper limit of 2 and below the upper limit of 3 which in the 4 points scale of strongly agreed, agreed, disagreed and strong disagreed are all on the "agreed" level. Since the means of items are on the same level of agreement, it implies that the five groups of respondents were agreeing on the influence of level of education on the utilization of prescribed eyeglasses. This therefore suggested that level of education has positive influence on the utilization of prescribed eyeglasses among staff of tertiary institutions in Akwa Ibom State, Nigeria.

\section{Research Question 4:}

How does profession influence the utilization of prescribed eyeglasses among staff of tertiary institutions in Akwa Ibom State, Nigeria?

Table 4: Mean, Standard Deviation and Mean of Items of Scores of Utilization of Prescribed Eyeglasses among Staff of Tertiary Institutions in Akwa Ibom State of Nigeria, based on Profession. $\quad(\mathbf{N}=\mathbf{8 8 2})$ Group Statistics

\begin{tabular}{l|c|c|c|c|c}
\hline Profession & $\mathbf{N}$ & $\begin{array}{c}\text { Mean } \\
(\bar{x})\end{array}$ & $\begin{array}{l}\text { Standard } \\
\text { Deviation }\end{array}$ & $\begin{array}{l}\text { Mean } \\
\text { of Items }\end{array}$ & Remarks \\
\hline $\begin{array}{l}\text { Administrative/technical } \\
\begin{array}{l}\text { Staff } \\
\text { Academic Staff }\end{array}\end{array}$ & 602 & 151.31 & 9.64 & 2.85 & Agreed \\
\hline
\end{tabular}


The results in Table 4 show the mean, standard deviation and mean of item of scores of the utilization of prescribed eyeglasses among staff of tertiary institutions in Akwa Ibom State, based on their professions. The 602 administrative/technical staff respondents had a higher mean of 151.31 and a standard deviation of 9.64; while the 280 academic staff respondents had mean of 149.16 with a standard deviation of 8.63 . Table 4 also indicates mean of items of 2.85 and 2.81 for the administrative/technical staff and the academics respectively. The mean of items of the two professorial groups of 2.85 and 2.81 are above the upper limit of 2 and below the upper limit 3 which in the 4 points scale of strongly agreed, agreed, disagreed and strongly disagreed are on the "agreed" level. Since the means of items (2.85 and 2.81) are in the same level of agreement, it implies that the two professional groups of the respondents were agreeing on the influence of profession on the utilization of prescribed eyeglasses. This therefore suggested that profession has positive influence on the utilization of prescribed eyeglasses among staff of tertiary institutions in Akwa Ibom State, Nigeria.

\section{Research Question 5:}

How do years of service influence the utilization of prescribed eyeglasses among staff of tertiary institutions in Akwa Ibom State, Nigeria?

Table 5: Mean, Standard Deviation and Mean of Items of Scores of Utilization of Prescribed Eyeglasses among Staff of Tertiary Institutions in Akwa Ibom State of Nigeria, based on Years of Service $(\mathbf{N}=\mathbf{8 8 2})$

\begin{tabular}{l|c|c|c|c|c}
\multicolumn{7}{c}{ Group Statistics } \\
\hline Years of Service & $\mathbf{N}$ & $\begin{array}{c}\text { Mean } \\
(\bar{x})\end{array}$ & $\begin{array}{l}\text { Standard } \\
\text { Deviation }\end{array}$ & $\begin{array}{l}\text { Mean of } \\
\text { Items }\end{array}$ & Remark \\
\hline Below 10 years & 67 & 146.82 & 10.50 & 2.77 & Agreed \\
11 to 20 years & 204 & 149.69 & 9.92 & 2.82 & Agreed \\
21 to 30 years & 446 & 151.32 & 9.44 & 2.86 & Agreed \\
31 years and above & 165 & 151.47 & 7.48 & 2.86 & Agreed \\
\hline
\end{tabular}

The results in Table 5 show the mean, standard deviation and mean of items of scores of the utilization of prescribed eyeglasses among staff of tertiary institutions in Akwa Ibom State, based on their years of service. The 165 respondents who had served for 31 years and above had the highest mean, 151.47 and standard deviation of 7.48; followed by 446 respondents who had served for 21 to 30 years, with mean of 151.32 and standard deviation of 9.44. The respondents whose years of service fell between 11 and 20 years had mean of 149.69 and standard deviation of 9.92; while those that served below 10 years had the lowest mean of 146.82 and a standard deviation of 10.50. Table 5 also indicates the mean of items of the four groups of respondents: the respondents who served below 10years, those of 11 to 20years, those of 21 to 30years and those of 31years and above as 2.77, 2.82, 2.86, and 2.86 respectively. The mean of items, 2.77, 2.82, 2.86 and 2.86 are above the upper limit of 2 and below the upper limit of 3 which in the 4 points scale of strongly agreed, agreed, disagreed and strongly disagreed fell on " "agreed" level. Since the means of items $(2.77,2.82,2.86$ and 2.86) are on the same level of agreement, it implies that the four groups of respondents of different years of service were agreeing on the influence of years of service on the utilization of prescribed eyeglasses. This therefore suggested that years of service have positive influence on the utilization of prescribed eyeglasses among staff of tertiary institutions in Akwa Ibom State, Nigeria.

Research Question 6:

How does income status influence the utilization of prescribed eyeglasses among staff of tertiary institutions in Akwa Ibom State, Nigeria?

Table 6: Mean, Standard Deviation and Mean of Items of Scores of Utilization of Prescribed Eyeglasses among Staff of Tertiary Institutions in Akwa Ibom State of Nigeria, based on Income Status (N=882)

\begin{tabular}{|c|c|c|c|c|c|}
\hline \multicolumn{6}{|c|}{ Group Statistics } \\
\hline $\begin{array}{l}\text { Income Status (monthly } \\
\text { earnings) }\end{array}$ & $\mathbf{N}$ & $\begin{array}{c}\text { Mean } \\
(\bar{x})\end{array}$ & $\begin{array}{l}\text { Standard } \\
\text { Deviation }\end{array}$ & $\begin{array}{l}\text { Mean } \\
\text { of Item }\end{array}$ & Remark \\
\hline Below $\$ 150,000$ & 127 & 150.82 & 9.19 & 2.85 & Agreed \\
\hline$\# 151,000$ to $¥ 250,000$ & 346 & 147.82 & 10.77 & 2.79 & Agreed \\
\hline$\$ 251,000$ to $\$ 350,000$ & 334 & 152.90 & 8.63 & 2.88 & Agreed \\
\hline$\$ 351,000$ to $¥ 450,000$ & 49 & 154.27 & 2.82 & 2.91 & Agreed \\
\hline$¥ 451,000$ and above & 26 & 150.96 & 8.09 & 2.85 & Agreed \\
\hline
\end{tabular}


The results in Table 6 show the mean, standard deviation and mean of items of scores of the utilization of prescribed eyeglasses among staff of tertiary institutions in Akwa Ibom State, based on income status. The 49 respondents whose income status fell between $\$ 351,000$ and $\$ 450,000$ had the highest mean, 154.27 and standard deviation of 2.82; followed by the mean of 334 respondents whose monthly earnings fell between $\$ 251,000$ and $\$ 350,000$ as 152.90 and standard deviation of 8.63. The 26 respondents with income status of $\$ 451,000$ and above had mean of 150.97 and standard deviation of 8.092 . Those with income status below $\$ 150,000$ per month had mean of 150.82; and standard deviation of 9.19; while 346 respondents whose income status fell between $\$ 151,000$ and $¥ 250,000$ had the lowest mean, 147.82 and a standard deviation of 10.77 . The mean of items, 2.85, $2.79,2.88,2.90$ and 2.85 are also reflected for the five groups of respondents of different income groups, from those of below $\$ 150,000$ to those of $\$ 451,000.00$ and above respectively. These means of items of $(2.85,2.79$, $2.88,2.90$ and 2.85) of the five income groups are above the upper limit of 2 and below the upper limit of 3, which in the 4 points scale of strongly agreed, agreed, disagreed and strongly disagreed are on the "agreed" level. Since these means of items are on the same level of agreement, it implies that the five groups of respondents of different monthly earnings were agreeing on the influence of income status on the utilization of prescribed eyeglasses. This therefore suggested that income status has positive influence on the utilization of prescribed eyeglasses among staff of tertiary institutions in Akwa Ibom State, Nigeria.

\section{Research Question 7:}

How does age of onset (of vision impairment) influence the utilization of prescribed eyeglasses among staff of tertiary institutions in Akwa Ibom State, Nigeria?

Table 7: Mean, Standard Deviation and Mean of Items of Scores of Utilization of Prescribed Eyeglasses among Staff of Tertiary Institutions in Akwa Ibom State of Nigeria, based on Age of Onset (of Vision Impairment).

$(\mathbf{N}=\mathbf{8 8 2})$

\section{Group Statistics}

\begin{tabular}{l|c|c|c|c|c}
\hline Age of Onset (of Vision Impairment) & $\mathbf{N}$ & $\begin{array}{c}\text { Mean } \\
(\overline{\boldsymbol{x}})\end{array}$ & $\begin{array}{l}\text { Standard } \\
\text { Deviation }\end{array}$ & $\begin{array}{l}\text { Mean } \\
\text { of Items }\end{array}$ & Remarks \\
\hline Childhood Onset (4-12yrs) & 67 & 146.82 & 10.50 & 2.77 & Agreed \\
Adolescence Onset (13-19years) & 204 & 149.69 & 9.92 & 2.82 & Agreed \\
Young Adult Onset(20-39years) & 165 & 151.47 & 7.48 & 2.86 & Agreed \\
Middle Age Onset (40-59years) & 446 & 151.32 & 9.44 & 2.86 & Agreed \\
\hline
\end{tabular}

The results in Table 7 show the mean, standard deviation and mean of item of scores of the utilization of prescribed eyeglasses among staff of tertiary institutions in Akwa Ibom State, based on the various ages of onset of vision impairment that made the respondents to use the prescribed eyeglasses. A total of 165 respondents who had onset of their vision problem at young adult age (20-39 years) had the highest mean of 151.47 and standard deviation of 7.48; followed by 446 respondents who had onset of their vision impairments at "middle age", (40 to 59years), with the mean of 151.32 and standard deviation of 9.44 . The 67 respondents who had onset of vision impairment from their childhood had the lowest mean, 146.81 and standard deviation of 10.50; followed by 204 respondents that had onset of vision impairment from their adolescence (13-19years) with mean of 149.69 and a standard deviation of 9.92. None of the respondents had onset of vision impairment at old age. Table 7 also shows mean of items of the four groups of respondent with different ages of onset of vision impairments as 2.77, 2.82, 2.86 and 2.86 respectively. The four means of items $(2.77,2.82,2.86$ and 2.86) are above the upper limit of 2 and below the upper limit of 3 which in the 4 point scale of strongly agreed, agreed, disagreed and strongly disagreed are on the "agreed" level. Since these four means of items $(2.77,2.82,2.86$ and 2.86) are of the same level of agreement, it implies that the four groups of respondents with different ages of onset were agreeing on the influence of age of onset on the utilization of prescribed eyeglasses. This therefore suggested that age of onset has positive influence on the utilization of prescribed eyeglasses among staff of tertiary institutions in Akwa Ibom State, Nigeria.

\section{Research Question 8:}

How do attitudes of staff toward prescribed eyeglasses influence their utilization in tertiary institutions in Akwa Ibom State, Nigeria? 
Table 8: Mean, Standard Deviation and Mean of Items of Scores of Utilization of Prescribed Eyeglasses among Staff of Tertiary Institutions in Akwa Ibom State of Nigeria, based on Attitudes( $\mathbf{N}=\mathbf{8 8 2})$

\section{Group Statistics}

\begin{tabular}{l|c|c|c|l|l}
\hline Staff Attitudes & $\mathbf{N}$ & $\begin{array}{c}\text { Mean } \\
(\bar{x})\end{array}$ & $\begin{array}{l}\text { Standard } \\
\text { Deviation }\end{array}$ & $\begin{array}{l}\text { Mean } \\
\text { of Items }\end{array}$ & Remarks \\
\hline Positive attitudes & 686 & 154.60 & 3.69 & 2.92 & Agreed \\
Negative attitudes & 196 & 136.71 & 9.99 & 2.58 & Agreed \\
\hline
\end{tabular}

The results in Table 8 indicate the mean, standard deviation and mean of items of scores of staff attitudes toward the utilization of prescribed eyeglasses in tertiary institutions in Akwa Ibom State, Nigeria. A total of 686 respondents had positive attitudes towards the utilization of prescribed eyeglasses with a higher mean of 154.60 and standard deviation of 3.69; while the mean of the remaining 196 respondents with negative attitudes was 136.71 and a standard deviation of 9.99 . Table 8 also reveals mean of item of the two groups of respondents with positive and negative attitudes as 2.92 and 2.58 respectively. The mean of items of the two groups of respondent, 2.92 and 2.58 are above the upper limit of 2 and below the limit of 3 which in the 4 points scale of strongly agreed, agreed, disagreed and strongly disagreed are on the "agreed" level. Since these means of items are on the same level of agreement, it implies that the two groups of respondents were agreeing on the influence of staff attitudes toward the utilization of prescribed eyeglasses. This therefore suggested that staff attitudes toward prescribed eyeglasses have positive influence on their utilization in the tertiary institutions in Akwa Ibom State, Nigeria.

\section{Research Question 9:}

How do beliefs influence the utilization of prescribed eyeglasses among staff of tertiary institutions in Akwa Ibom State, Nigeria?

Table 9: Mean, Standard Deviation and Mean of items of Scores of Utilization of Prescribed Eyeglasses among Staff of Tertiary Institutions in Akwa Ibom State, based on Beliefs $\quad(\mathrm{N}=882)$

\section{Group Statistics}

\begin{tabular}{l|c|c|c|c|c}
\hline Beliefs & $\mathbf{N}$ & $\begin{array}{c}\text { Mean } \\
(\bar{x})\end{array}$ & $\begin{array}{l}\text { Standard } \\
\text { Deviation }\end{array}$ & $\begin{array}{l}\text { Mean } \\
\text { of Items }\end{array}$ & Remarks \\
\hline Positive beliefs & 865 & 150.52 & 9.44 & 2.84 & Agreed \\
Negative beliefs & 17 & 155.94 & 1.02 & 2.94 & Agreed \\
\hline
\end{tabular}

The results in Table 9 show the mean, standard deviation and mean of items of scores of the utilization of prescribed eyeglasses among staff of tertiary institutions in Akwa Ibom State, based on their beliefs. The mean of 865 respondents with positive beliefs was 150.52 and a standard deviation of 9.44; while that of 17 respondents with negative beliefs was 155.94 and a standard deviation of 1.03. The table also shows the mean of items of 2.84 and 2.94 for the respondents with positive and negative beliefs respectively. The two means of items $(2.84$ and 2.94) are above the upper limit of 2 and below the upper limit of 3 which in the 4 points scale of strongly agreed, agreed, disagreed and strongly disagreed are on the "agreed" level. Since the two means of items are on the same level of agreement, it implies that the two groups of respondents with positive and negative beliefs were agreeing on the influence of beliefs on the utilization of prescribed eyeglasses. This therefore suggested that beliefs have positive influence on the utilization of prescribed eyeglasses among staff of tertiary institutions in Akwa Ibom State, Nigeria.

\section{(B) Testing of Research Hypotheses}

Research Hypothesis 1: Age has no significant influence on the utilization of prescribed eyeglasses among staff of tertiary institutions in Akwa Ibom State, Nigeria. 
Table 10: The Summary of One-way Analysis of Variance (ANOVA) of Scores of the Utilization of Prescribed Eyeglasses among Staff of Tertiary Institutions in Akwa Ibom State, based on Age. $(\mathbf{N}=882)$

\section{Group Statistics}

\begin{tabular}{lccccc}
\hline & Sum of squares & df & mean square & F-cal & F-critical \\
& & & & & \\
\hline Between Groups & 80.21 & 2 & 40.10 & .46 & 3.00 \\
Within Groups & 77484.07 & 879 & 88.15 & & \\
Total & 77564.28 & 881 & & & \\
\hline
\end{tabular}

Not significant at .05 level

The result in Table 10 shows the summary of one-way analysis of variance (ANOVA) of scores of the utilization of prescribed eyeglasses among staff of tertiary institutions in Akwa Ibom State based on age. Since the calculated F-value (F-cal) of 0.46 is less than the critical F-value of 3.00 which was not significant at .05 levels, at 2 and 879 degrees of freedom, the null hypothesis which stated that age has no significant influence on the utilization of prescribed eyeglasses among staff of tertiary institutions in Akwa Ibom State was accepted. The result therefore confirmed that age has no significant influence on the utilization of prescribed eyeglasses among staff of tertiary institutions in Akwa Ibom State.

Hypothesis 2: Gender has no significant influence on the utilization of prescribed eyeglasses among staff of tertiary institutions in Akwa Ibom State.

Table 11: The Summary of Independent t-test Analysis of Scores of the Utilization of Prescribed Eyeglasses among Staff of Tertiary Institutions in Akwa Ibom State based on gender. ( $\mathbf{N = 8 8 2})$

\section{Group Statistics}

\begin{tabular}{lcccll}
\hline Gender & $\mathbf{N}$ & $\begin{array}{c}\text { Mean } \\
(\bar{x})\end{array}$ & Standard deviation (SD) & t-cal & t-critical \\
& & & & \\
\hline Female & 501 & 151.07 & 8.81 & 1.61 & 1.96 \\
Male & 381 & 150.05 & 10.07 & & \\
\hline
\end{tabular}

Not significant at .05 alpha level and 880 degrees of freedom.

The results in Table 11 show summary of t-test analysis of the scores of the utilization of prescribed eyeglasses among staff of tertiary institutions in Akwa Ibom State based on gender. Since the calculated t-test value (t-cal) of 1.61 is less than critical table t-value of 1.96, which was not significant at .05 level and 880 degrees of freedom, the null hypothesis that stated that gender has no significant influence on the utilization of prescribed eyeglasses among staff of tertiary institutions in Akwa Ibom State was accepted. The result therefore confirmed that gender has no significant influence on the utilization of prescribed eyeglasses among staff of tertiary institutions in Akwa Ibom State, Nigeria.

\section{Hypothesis 3:}

Level of education has no significant influence on the utilization of prescribed eyeglasses among staff of tertiary institutions in Akwa Ibom State, Nigeria.

Table 12: The Summary of One-way Analysis of Variance (ANOVA) of Scores of the Utilization of Prescribed Eyeglasses among Staff of Tertiary Institutions in Akwa Ibom State, based on Level of Education $(\mathbf{N}=\mathbf{8 8 2})$

Group Statistics

\begin{tabular}{lccccc}
\hline & Sum of squares & df & mean square & F-cal & F-critical \\
\hline Between Groups & 1130.87 & 4 & 282.72 & 3.24 & 2.38 \\
Within groups & 76433.41 & 877 & 87.15 & & \\
Total & 77564.28 & 881 & & & \\
\hline
\end{tabular}

Significant at .05 alpha levels, at 4 and 877 degrees freedom

The results in Table 12 show the summary of one-way analysis of variance of the scores of utilization of prescribed eyeglasses among staff of tertiary institutions in Akwa Ibom State based on level of education. Since the calculated 
F-value (F-cal) of 3.24 is greater than the critical F- value (F-crit) of 2.38 at .05 level of significance, at 4 and 877 degrees of freedom, the null hypothesis which stated that level of education has no significant influence on the utilization of prescribed eyeglasses among staff of tertiary institutions in Akwa Ibom State was rejected. The result therefore implied that level of education has significant influence on the utilization of prescribed eyeglasses among staff of tertiary institutions in Akwa Ibom State, Nigeria.

Post hoc test was conducted based on the result of the significant influence on utilization to determine the pair that brought about the significant influence. The result shows that all the pairs with asterisks in mean scores are the ones brought about the influence. This implied that there was an existed statistically significant influence of level of education on the utilization of prescribed eyeglasses between the respondents with master degree level and those of doctorate degree.

\section{Table 13: Post Hoc Test of the Significant Influence of Level of Education}

Scheffe

Multiple Comparisons

\begin{tabular}{|c|c|c|c|c|c|c|}
\hline \multirow[t]{2}{*}{ (I) Level of education } & \multirow{2}{*}{$\begin{array}{l}\text { (J) Level of } \\
\text { education }\end{array}$} & \multirow{2}{*}{$\begin{array}{l}\text { Mean Difference } \\
(\mathrm{I}-\mathrm{J})\end{array}$} & \multirow{2}{*}{$\begin{array}{l}\text { Std. } \\
\text { Error }\end{array}$} & \multirow[t]{2}{*}{ Sig. } & \multicolumn{2}{|c|}{ 95\% Confidence Interval } \\
\hline & & & & & $\begin{array}{l}\text { Lower } \\
\text { Bound }\end{array}$ & $\begin{array}{l}\text { Upper } \\
\text { Bound }\end{array}$ \\
\hline \multirow{4}{*}{ Diploma level } & $\begin{array}{l}\text { HND/First Degree } \\
\text { Level }\end{array}$ & 1.43769 & 1.33197 & .884 & -2.6738 & 5.5492 \\
\hline & Master Degree Level & -.49315 & 1.34206 & .998 & -4.6358 & 3.6495 \\
\hline & $\begin{array}{l}\text { Doctorate Degree } \\
\text { Level }\end{array}$ & 2.44350 & 1.41246 & .559 & -1.9165 & 6.8035 \\
\hline & $\begin{array}{l}\text { Professional } \\
\text { Attainment }\end{array}$ & .58824 & 2.01643 & .999 & -5.6361 & 6.8125 \\
\hline \multirow{3}{*}{$\begin{array}{l}\text { HND/First Degree } \\
\text { Level }\end{array}$} & Diploma level & $\begin{array}{l}-1.43769 \\
-193085\end{array}$ & $\begin{array}{r}1.33197 \\
75497\end{array}$ & $\begin{array}{r}.884 \\
163\end{array}$ & $\begin{array}{l}-5.5492 \\
-42613\end{array}$ & $\begin{array}{r}2.6738 \\
3996\end{array}$ \\
\hline & $\begin{array}{l}\text { Doctorate Degree } \\
\text { Level }\end{array}$ & 1.00581 & .87401 & .857 & -1.6921 & 3.7037 \\
\hline & $\begin{array}{l}\text { Professional } \\
\text { Attainment }\end{array}$ & -.84946 & 1.68370 & .993 & -6.0467 & 4.3478 \\
\hline \multirow{4}{*}{ Master Degree Level } & Diploma level & .49315 & 1.34206 & .998 & -3.6495 & 4.6358 \\
\hline & $\begin{array}{l}\text { HND/First Degree } \\
\text { Level }\end{array}$ & 1.93085 & .75497 & .163 & -.3996 & 4.2613 \\
\hline & $\begin{array}{l}\text { Doctorate Degree } \\
\text { Level }\end{array}$ & $2.93665^{*}$ & .88930 & .028 & .1916 & 5.6818 \\
\hline & $\begin{array}{l}\text { Professional } \\
\text { Attainment }\end{array}$ & 1.08139 & 1.69169 & .982 & -4.1405 & 6.3033 \\
\hline \multirow{4}{*}{$\begin{array}{l}\text { Doctorate Degree } \\
\text { Level }\end{array}$} & Diploma level & -2.44350 & 1.41246 & .559 & -6.8035 & 1.9165 \\
\hline & $\begin{array}{l}\text { HND/First Degree } \\
\text { Level }\end{array}$ & -1.00581 & .87401 & .857 & -3.7037 & 1.6921 \\
\hline & Master Degree Level & $-2.93665^{*}$ & .88930 & .028 & -5.6818 & -.1916 \\
\hline & $\begin{array}{l}\text { Professional } \\
\text { Attainment }\end{array}$ & -1.85527 & 1.74806 & .890 & -7.2512 & 3.5407 \\
\hline \multirow{4}{*}{$\begin{array}{l}\text { Professional } \\
\text { Attainment }\end{array}$} & Diploma level & -.58824 & 2.01643 & .999 & -6.8125 & 5.6361 \\
\hline & $\begin{array}{l}\text { HND/First Degree } \\
\text { Level }\end{array}$ & .84946 & 1.68370 & .993 & -4.3478 & 6.0467 \\
\hline & Master Degree Level & -1.08139 & 1.69169 & .982 & -6.3033 & 4.1405 \\
\hline & $\begin{array}{l}\text { Doctorate Degree } \\
\text { Level }\end{array}$ & 1.85527 & 1.74806 & .890 & -3.5407 & 7.2512 \\
\hline
\end{tabular}

The Mean difference is significant at .05 alpha level 
Hypothesis 4: Profession has no significant influence on the utilization of prescribed eyeglasses among staff of tertiary institutions in Akwa Ibom State.

Table 14: The Summary of Independent t- test Analysis of the Scores of the Utilization of Prescribed Eyeglasses among Staff of Tertiary Institutions in Akwa Ibom State of Nigeria, based on profession.) $(N=$ 882)

\section{Group Statistics}

\begin{tabular}{lccccc}
\hline Profession & $\mathbf{N}$ & $\begin{array}{c}\text { Mean } \\
(\bar{x})\end{array}$ & Standard Deviation & t-cal & t-critical \\
\hline $\begin{array}{l}\text { Administrative/ } \\
\text { Technical staff }\end{array}$ & 602 & 151.31 & 9.64 & 3.19 & 1.96 \\
& & & \\
Academic staff & 280 & 149.16 & 8.63 & \\
\hline Significant at .05 alpha levels and 880 degrees of freedom
\end{tabular}

The results in Table 13 show the summary of the independent t-test analysis of the scores of the utilization of prescribed eyeglasses among staff of tertiary institutions in Akwa Ibom State based on profession. Since the calculated t-value ( $\mathrm{t}$-cal) of 3.19 is greater than critical t-value (t-critical) of 1.96 at .05 alpha level and 880 degrees of freedom, the null hypothesis which stated that profession has no significant influence on the utilization of prescribed eyeglasses among staff of tertiary institutions in Akwa Ibom State was rejected. The result therefore implied that profession has significant influence on the utilization of prescribed eyeglasses among staff of tertiary institutions in Akwa Ibom State, Nigeria.

\section{Hypothesis 5:}

Years of service have no significant influence on the utilization of prescribed eyeglasses among staff of tertiary institutions in Akwa Ibom State, Nigeria.

Table15: The Summary of One-way Analysis of Variance of the Scores of the Utilization of Prescribed Eyeglasses among Staff of Tertiary Institutions in Akwa Ibom State, based on the Years of Service. ( $N=$ 882)

\section{Group Statistics}

\begin{tabular}{lccccc}
\hline & Sum of squares & df & mean square & F-cal & F-critical \\
\hline Between Groups & 1480.65 & 3 & 493.55 & 5.70 & 2.61 \\
Within Groups & 76083.63 & 878 & 86.66 & & \\
Total & 77564.28 & 881 & & & \\
\hline
\end{tabular}

Significant at .05 alpha levels, at 3 and 878 degrees of freedom

The results in Table 14 show the summary of one-way analysis of variance of the scores of the utilization of prescribed eyeglasses among staff of tertiary institutions in Akwa Ibom State based on years of service. Since the F-cal of 5.70 is greater than the F- critical of 2.61 at .05level of significance, at 3 and 878 degrees of freedom, the null hypothesis which stated that years of service have no significant influence on the utilization of prescribed eyeglasses among staff of tertiary institutions in Akwa Ibom State was rejected. The result therefore implied that years of service have significant influence on the utilization of prescribed eyeglasses among staff of tertiary institutions in Akwa Ibom State.

Based on the result of significant influence of years of service on the utilization of prescribed eyeglasses, post hoc test was conducted to determine the pair that brought about the significant influence. The result shows that all the pairs with asterisks in mean difference are the ones bringing about the significant influence. This implied that there was a statistically significant influence of years of service on the utilization of prescribed eyeglasses between the respondents that have worked for 31 years and above and those below 10years of service. 
Table 16: Post Hoc Test of the Significant Influence of Years of Service

Multiple Comparisons

Scheffe

\begin{tabular}{|c|c|c|c|c|c|c|}
\hline \multirow{2}{*}{$\begin{array}{l}\text { (I) Years of } \\
\text { service }\end{array}$} & \multirow{2}{*}{$\begin{array}{l}\text { (J) Years of } \\
\text { service }\end{array}$} & \multirow{2}{*}{$\begin{array}{l}\text { Mean Difference (I- } \\
\text { J) }\end{array}$} & \multirow{2}{*}{$\begin{array}{l}\text { Std. } \\
\text { Error }\end{array}$} & \multirow[t]{2}{*}{ Sig. } & \multicolumn{2}{|c|}{ 95\% Confidence Interval } \\
\hline & & & & & $\begin{array}{l}\text { Lower } \\
\text { Bound }\end{array}$ & $\begin{array}{l}\text { Upper } \\
\text { Bound }\end{array}$ \\
\hline \multirow{3}{*}{ Below 10 years } & 11 to 20 years & -2.86538 & 1.31078 & .190 & -6.5368 & .8060 \\
\hline & 21 to 30 years & $-4.49749^{*}$ & 1.21970 & .004 & -7.9138 & -1.0812 \\
\hline & $\begin{array}{l}31 \text { years and } \\
\text { above }\end{array}$ & $-4.64577^{*}$ & 1.34854 & .008 & -8.4229 & -.8686 \\
\hline \multirow{3}{*}{11 to 20 years } & Below 10 years & 2.86538 & 1.31078 & .190 & -.8060 & 6.5368 \\
\hline & 21 to 30 years & -1.63211 & .78681 & .231 & -3.8359 & .5717 \\
\hline & $\begin{array}{l}31 \text { years and } \\
\text { above }\end{array}$ & -1.78039 & .97466 & .343 & -4.5103 & .9496 \\
\hline \multirow{3}{*}{21 to 30 years } & Below 10 years & $4.49749^{*}$ & 1.21970 & .004 & 1.0812 & 7.9138 \\
\hline & 11 to 20 years & 1.63211 & .78681 & .231 & -.5717 & 3.8359 \\
\hline & $\begin{array}{l}31 \text { years and } \\
\text { above }\end{array}$ & -.14828 & .84822 & .999 & -2.5241 & 2.2275 \\
\hline \multirow{3}{*}{$\begin{array}{l}31 \text { years and } \\
\text { above }\end{array}$} & Below 10 years & $4.64577^{*}$ & 1.34854 & .008 & .8686 & 8.4229 \\
\hline & 11 to 20 years & 1.78039 & .97466 & .343 & -.9496 & 4.5103 \\
\hline & 21 to 30 years & .14828 & .84822 & .999 & -2.2275 & 2.5241 \\
\hline
\end{tabular}

The mean difference is significant at the .05 level.

\section{Hypothesis 6:}

Income status has no significant influence on the utilization of prescribed eyeglasses among staff of tertiary institutions in Akwa Ibom State, Nigeria.

Table 17: The Summary of One-way Analysis of Variance of the Scores of the Utilization of Prescribed Eyeglasses among Staff of Tertiary Institutions in Akwa Ibom State, based on Income Status. $(\mathbf{N}=\mathbf{8 8 2})$

\section{Group Statistics}

\begin{tabular}{lccccc}
\hline & Sum of squares & df & mean square & F-cal & F-critical \\
\hline Between Groups & 5098.15 & 4 & 1274.54 & 15.43 & 2.38 \\
Within Groups & 72466.13 & 877 & 82.63 & & \\
Total & 77564.28 & 881 & & & \\
\hline
\end{tabular}

Significant at .05 alpha levels, at 4 and 877 degrees of freedom

The results in Table 15 show the summary of one-way analysis of the scores of income status on utilization of prescribed eyeglasses among staff of tertiary institutions in Akwa Ibom State. Since the F- cal of 15.43 is greater than the F-critical of 2.38 at .05 levels of significance, at 4 and 877 degrees of freedom; the null hypothesis which stated that income status has no significant influence on the utilization of prescribed eyeglasses among staff of tertiary institutions in Akwa Ibom State was rejected. The result therefore implied that income status has significant influence on the utilization of prescribed eyeglasses among staff of tertiary institutions in Akwa Ibom State.

Based on the result, post hoc test was conducted to determine the pair that brought about the significant influence. The post hoc test result shows that all the pairs with asterisks in mean difference are the ones bringing about the noted significant influence. Thus, the respondents whose income level were below $\$ 150,000$ and those of $\$ 151,000$ to $\mathrm{N} 250,000$ as well as those of $\$ 351,000$ to $\mathrm{N} 450.000$ monthly income were the ones that brought about the significant influence. This therefore, implied that income status has statistically significant influence on the utilization of prescribed eyeglasses among staff of tertiary institutions in Akwa Ibom State. 
Table 18: Post Hoc Test of the Significant Influence of Income Status

Scheffe

\author{
Multiple Comparisons
}

\begin{tabular}{|c|c|c|c|c|c|c|}
\hline \multirow[t]{2}{*}{ (I) Income status } & \multirow[t]{2}{*}{ (J) Income status } & \multirow[t]{2}{*}{ Mean Difference (I-J) } & \multirow[t]{2}{*}{ Std. Error } & \multirow[t]{2}{*}{ Sig. } & \multicolumn{2}{|c|}{$95 \%$ Confidence Interval } \\
\hline & & & & & Lower Bound & Upper Bound \\
\hline \multirow{4}{*}{ below 150,000} & 151,000 to 250,000 & $2.99520^{*}$ & 94310 & .040 & .0840 & 5.9064 \\
\hline & 251,000 to 350,000 & -2.07931 & .94764 & .308 & -5.0045 & .8459 \\
\hline & 351,000 to 450,000 & -3.44641 & 1.52871 & .280 & -8.1652 & 1.2724 \\
\hline & 451,000 and above & -.14264 & 1.95670 & 1.000 & -6.1826 & 5.8973 \\
\hline \multirow{4}{*}{151,000 to 250,000} & below 150,000 & $-2.99520^{*}$ & .94310 & .040 & -5.9064 & -.0840 \\
\hline & 251,000 to 350,000 & $-5.07450^{*}$ & .69729 & .000 & -7.2269 & -2.9221 \\
\hline & 351,000 to 450,000 & $-6.44161^{*}$ & 1.38749 & .000 & -10.7245 & -2.1587 \\
\hline & 451,000 and above & -3.13784 & 1.84848 & .578 & -8.8437 & 2.5680 \\
\hline \multirow{4}{*}{251,000 to 350,000} & below 150,000 & 2.07931 & .94764 & 308 & -.8459 & 5.0045 \\
\hline & 151,000 to 250,000 & $5.07450^{*}$ & .69729 & .000 & 2.9221 & 7.2269 \\
\hline & 351,000 to 450,000 & -1.36710 & 1.39058 & 915 & -5.6595 & 2.9253 \\
\hline & 451,000 and above & 1.93667 & 1.85080 & .895 & -3.7764 & 7.6497 \\
\hline \multirow{4}{*}{351,000 to 450,000} & below 150,000 & 3.44641 & 1.52871 & .280 & -1.2724 & 8.1652 \\
\hline & 151,000 to 250,000 & $6.44161^{*}$ & 1.38749 & .000 & 2.1587 & 10.7245 \\
\hline & 251,000 to 350,000 & 1.36710 & 1.39058 & 915 & -2.9253 & 5.6595 \\
\hline & 451,000 and above & 3.30377 & 2.20553 & .691 & -3.5043 & 10.1118 \\
\hline \multirow{4}{*}{451,000 and above } & below 150,000 & .14264 & 1.95670 & 1.000 & -5.8973 & 6.1826 \\
\hline & 151,000 to 250,000 & 3.13784 & 1.84848 & .578 & -2.5680 & 8.8437 \\
\hline & 251,000 to 350,000 & -1.93667 & 1.85080 & .895 & -7.6497 & 3.7764 \\
\hline & 351,000 to 450,000 & -3.30377 & 2.20553 & .691 & -10.1118 & 3.5043 \\
\hline
\end{tabular}

The Mean difference is significant at the .05 level.

Hypothesis 7: Age of onset (of vision impairment) has no significant influence on the utilization of prescribed eyeglasses among staff of tertiary institutions in Akwa Ibom State, Nigeria.

Table 19: The Summary of One-way Analysis of Variance of Scores of the Utilization of Prescribed Eyeglasses among Staff of Tertiary Institutions in Akwa Ibom State, based on Age of Onset $(\mathbf{N}=882)$

\begin{tabular}{|c|c|c|c|c|c|}
\hline \multicolumn{6}{|c|}{ Group Statistics } \\
\hline & m of Squares & df & Mean Square & F-cal & F-critical \\
\hline Between Groups & 1480.65 & 3 & 493.55 & 5.70 & 2.61 \\
\hline Within Groups & 76083.63 & 878 & 86.66 & & \\
\hline Total & 77564.28 & 881 & & & \\
\hline
\end{tabular}

Significant at .05 levels, 3 and 878 degrees of freedom.

The results in Table 16 show the summary of one-way analysis of variance (ANOVA) of the scores of the utilization of prescribed eyeglasses among staff of tertiary institutions in Akwa Ibom State based on the age of onset. Since the F-cal of 5.70 is greater than the F-critical of 2.61 at .05level of significance; at 3 and 878 degrees of freedom, the null hypothesis which stated that age of onset has no significant influence on the utilization of prescribed eyeglasses among staff of tertiary institutions in Akwa Ibom State was rejected. This therefore implied that age of onset has statistical significant influence on the utilization of prescribed eyeglasses among staff of tertiary institutions in Akwa Ibom State, Nigeria.

Based on this significance influence, post hoc test was conducted to determine the pairs that brought about the significant influence. The result shows that all the pairs with asterisks in mean difference were the ones that brought about the significant influence of the age of onset on utilization of prescribed eyeglasses. This implied that there was a statistical significant influence of age of onset on the utilization of prescribed eyeglasses by the 
respondents whose onset of visual impairment started during their childhood, young adulthood and those that the onset of their vision impairment occurred during middle age.

Table 20: Post Hoc Test of the Significant Influence of Age of Onset

Scheffe

\section{Multiple Comparisons}

\begin{tabular}{|c|c|c|c|c|c|c|}
\hline \multirow[t]{2}{*}{ (I) Age of onset } & \multirow[t]{2}{*}{ (J) Age of onset } & \multirow{2}{*}{$\begin{array}{l}\text { Mean Difference (I- } \\
\text { J) }\end{array}$} & \multirow{2}{*}{$\begin{array}{l}\text { Std. } \\
\text { Error }\end{array}$} & \multirow[t]{2}{*}{ Sig. } & \multicolumn{2}{|c|}{ 95\% Confidence Interval } \\
\hline & & & & & $\begin{array}{l}\text { Lower } \\
\text { Bound }\end{array}$ & $\begin{array}{l}\text { Upper } \\
\text { Bound }\end{array}$ \\
\hline \multirow{3}{*}{ Childhood onset } & Adolescence onset & -2.86538 & 1.31078 & .190 & -6.5368 & .8060 \\
\hline & Young adult onset & $-4.49749^{*}$ & 1.21970 & .004 & -7.9138 & -1.0812 \\
\hline & Middle age onset & $-4.64577^{*}$ & 1.34854 & .008 & -8.4229 & -.8686 \\
\hline \multirow{3}{*}{$\begin{array}{l}\text { Adolescence } \\
\text { onset }\end{array}$} & Childhood onset & 2.86538 & 1.31078 & .190 & -.8060 & 6.5368 \\
\hline & Young adult onset & -1.63211 & .78681 & .231 & -3.8359 & .5717 \\
\hline & Middle age onset & -1.78039 & .97466 & .343 & -4.5103 & .9496 \\
\hline \multirow{3}{*}{ Young adult onset } & Childhood onset & $4.49749^{*}$ & 1.21970 & .004 & 1.0812 & 7.9138 \\
\hline & $\begin{array}{l}\text { Adolescences } \\
\text { onset }\end{array}$ & 1.63211 & .78681 & .231 & -.5717 & 3.8359 \\
\hline & Middle age onset & -.14828 & .84822 & .999 & -2.5241 & 2.2275 \\
\hline \multirow{3}{*}{ Middle age onset } & Childhood onset & $4.64577^{*}$ & 1.34854 & .008 & .8686 & 8.4229 \\
\hline & Adolescence onset & 1.78039 & .97466 & .343 & -.9496 & 4.5103 \\
\hline & Young adult onset & .14828 & .84822 & .999 & -2.2275 & 2.5241 \\
\hline
\end{tabular}

The mean difference is significant at the .05 level.

\section{Hypothesis 8:}

Attitudes of staff toward prescribed eyeglasses have no significant influence on their utilization in tertiary institutions in Akwa Ibom State, Nigeria.

Table 21: The Summary of Independent t-test Analysis of Scores of Staff Attitude toward the Utilization of Prescribed Eyeglasses in Tertiary Institutions in Akwa Ibom State, Nigeria. $(N=822)$

\section{Group Statistics}

\begin{tabular}{lccccl}
\hline Attitudes & $\mathbf{N}$ & $\begin{array}{c}\text { Mean } \\
(\bar{x})\end{array}$ & Standard Deviation & t-cal & t-critical \\
& & 154.60 & 3.69 & 2.36 & 1.96 \\
\hline Positive attitudes & 686 & 136.71 & 9.99 & & \\
Negative attitudes & 196 & S & & \\
\hline
\end{tabular}

Significant at .05 alpha levels and 880 degrees of freedom

The results in Table 17 show the summary of the t-test analysis of the scores of staff's attitudes toward the utilization of prescribed eyeglasses in tertiary institutions in Akwa Ibom State. Since the t- cal of 2.36 is greater than the t-critical of 1.96 at .05 alpha level and 880 degrees of freedom, the null hypothesis which stated that staff's attitudes have no significant influence toward the utilization of prescribed eyeglasses in tertiary institutions in Akwa Ibom State was rejected. The result therefore implied that staff's attitudes have significant influence toward the utilization of prescribed eyeglasses in tertiary institutions in Akwa Ibom State, Nigeria.

\section{Hypothesis 9:}

Beliefs have no significant influence on the utilization of prescribed eyeglasses among staff of tertiary institutions in Akwa Ibom State, Nigeria. 
Table 22: The Summary of Independent t-test Analysis of the Scores of the Utilization of Prescribed Eyeglasses among Staff of Tertiary Institutions in Akwa Ibom State, based on Beliefs. $(\mathrm{N}=882)$

\section{Group Statistics}

\begin{tabular}{lrrccc}
\hline Profession & N & $\begin{array}{r}\text { Mean } \\
(\bar{x})\end{array}$ & Standard Deviation & t-cal & t-critical \\
& & & & \\
& & & & \\
\hline Positive beliefs & 865 & 150.52 & 9.44 & 2.36 & 1.96 \\
Negative beliefs & 17 & 155.94 & 1.03 & & \\
\hline
\end{tabular}

Significant at .05 levels and 880 degrees of freedom

The results in Table 18 show the summary of t- test analysis of scores of the utilization of prescribed eyeglasses among staff of tertiary institutions in Akwa Ibom State based on beliefs. Since the t-cal of 2.36 is greater than tcritical value of 1.96 at .05 alpha level and 880 degrees of freedom, the null hypothesis which stated that beliefs have no significant influence on the utilization of prescribed eyeglasses among staff of tertiary institutions in Akwa Ibom State was rejected. This therefore meant that beliefs have significant influence on the utilization of prescribed eyeglasses among staff of tertiary institutions in Akwa Ibom State, Nigeria.

\section{(B) Discussion of findings}

\section{The Influence of Age on Utilization of Prescribed Eyeglasses}

The result of the one-way analysis of variance (ANOVA) in Table 10 revealed an absence (or nonexistence) of statistically significant influence of age on utilization of prescribed eyeglasses among staff of tertiary institutions in Akwa Ibom State, because the calculated F-value (F-cal) of 0.46 was less than the critical table Fvalue (F-critical) of 3.00. This might have related to the fact that vision impairment due to refractive errors usually affects people of all ages. The refractive error is common to all people; irrespective of their age-groups, race or culture. The children, adolescents, young adults and the aged people are commonly affected, requiring the use of prescribed eyeglasses as the most accessible treatment option. The finding is in agreement with that of Idu and Udom (2004) who acknowledged that utilization of prescribed eyeglasses for the treatment and correction of vision impairment due to refractive errors is not limited to people of any particular age, since the refractive errors affect people of all age-groups. However, Resniskoff et al (2008) observed greater use of prescribed eyeglasses in most adult populations of forty years and above in most parts of the world.

Similarly, Yanoff and Duker (2008) pointed out that the number of people that acquired and made use of prescribed eyeglasses increases as the age of people in any population increased. The authors explained that one of major reasons for the increase in the number of people that use prescribed eyeglasses in most adult population of about forty years of age and above always come from the burden of presbyopia; which is an age-related vision impairment that affects about $80 \%$ of adult in most populations of about 40 years and above globally. The authors further reiterated that those who didn't use eyeglasses in their childhood, adolescence and the early adult life will be added to the number of people that carried or continued with their eyeglasses to the middle age. This will lead to an increase in the number of people that use eyeglasses from forty years and above in any population.

Furthermore, Toit, Ranke, Naduvilath and Brein (2006) however found out from their study that old age was a barrier to the utilization of prescribed eyeglasses as well as other eye-care services. The reason has bearing to the fact that most elderly people with vision impairment are neglected and abandoned in some rural areas of Africa and the Caribbean Island because of their fatalistic concept of age; of which blindness is viewed as an inevitable component of old age. Therefore, the aged people with vision impairment that would have improved with the use of prescribed eyeglasses or other treatment options are neglected because poor vision and blindness are considered as components of old age.

\section{The influence of Gender on the Utilization of Prescribed Eyeglasses}

The result of the independent t-test analysis of the influence of gender on the utilization of prescribed eyeglasses in Table 11 yielded no significant influences of gender on the utilization of prescribed eyeglasses among staff of tertiary institutions in Akwa Ibom State, since the calculated t-test value (t-cal) of 1.61 was less than the critical table value (t-critical) of 1.96. The finding of absence (or non-existence) of statistically significant influence of gender on the utilization of prescribed eyeglasses in the study may be connected the fact that the 
refractive errors affect all people-both males and females, without respect to any particular gender. Since both males and females suffer from vision impairment due refractive errors, the utilization of prescribed eyeglasses is required by all persons with such refractive errors for treatment and correction of the vision impairment. Nevertheless, the majority of the respondents in the present study were females: 501 female respondents against 381 male respondents. This may have related to the fact that women always complain of any slight health problem or medical symptoms that affect them more than their male counterparts. It was therefore, possible to have greater number of female staff with vision impairment due to refractive errors, who visited eye-hospitals or eye-care centres to test their eyes and obtained prescribed eyeglasses, more than the males. A similar result was obtained by Nirmalan Krishnaiah and Shamannah (2006) who had also found non-statistically significant effect of gender on utilization eyeglasses in their study. More female respondents also participated in their study.

Similar findings of which the majority of those that sought eye-care services were females were also obtained by Baker, Barzegan, Barzegan and Calceron (2005) and Jin and Trope (2011); who had also reported more females (greater than males) to have utilized eye-care services in their studies. These authors attributed such finding in their studies to be related to the areas of their study; which had being in the developed countries-where gender do not constitute a barrier to the female's health-seeking behaviours. However, Fletcher, Donoghue, Devavaran and Murugan (2009) obtained a contrary finding, whereby more males were found to have obtained prescribed eyeglasses. But the majority of those that sought eye-care services and obtained eyeglasses are women in most other cases in most parts of the world.

\section{The Influence of Level of Education on the Utilization of Prescribed Eyeglasses}

The result of one-way analysis of variance in Table 12 revealed statistically significant influence of level of education on the utilization of prescribed eyeglasses among staff of tertiary institutions in Akwa Ibom State, since the F-cal of 3.24 was greater than F-crit. of 2.38. This was very possible because every aspect of learning at any level involve greater use of the learner's eyes and their visual systems. The highly educated people spent greater number of years in their studies, thereby exposing their eyes and the visual systems to greater level of near work activities that have higher tendency of exposing people's eyes to refractive errors, such near-work induced myopia and presbyopia. The finding of this present study is in line with the one obtained by the study of Goldschmidt and Jacobsen (2014), who acknowledged that highly educated people were more likely to have myopia than the less educated ones, which also implied higher tendency of utilization of prescribed eyeglasses for correction or other treatment options. Another recent study by Nirshah (2014) also affirmed that higher level of educational attainment (more years of studies) has strong association with higher tendency of developing refractive errors, explaining that the number of cases of myopia was significantly larger in subject with higher education than others with less education.

Furthermore, Nirshah (2014) explained that an increasing number of years of study may cause many people who wouldn't have had refractive errors, to develops such refractive errors, especially education induced myopia; in people without genetic implications. The author clarified that educational level was more important in predicting whether a particular individual will develop refractive error that require acquisition and utilization of prescribed eyeglasses than the genetic factors. The author concluded that people with higher level of education, who spent more years in reading, looking at computers and smart phones, have higher chances of developing refractive error-especially near sightedness (education induced myopia).

Similarly, Waldron (2014) observed that nearsightedness has risen from $25 \%$ to $41 \%$ in the United States population in the last four decades, thereby increasing the number of people that are using prescribed eyeglasses than before. The author reported that more people were getting admission to undergo extended programme of studies every year; thereby increasing the number of people with education induced myopia and greater use of eyeglasses. Liping, Jasmin and Yaugu (2010) also reported that the number of people that have education-induced myopia have reached much higher proportion in certain Asian countries in recent years where up to $90 \%$ of high school students and young adult are now living with myopia. This therefore implied that people with higher level of education have a greater tendency to use prescribed eyeglasses more than other with less or lower level of education.

\section{The Influence of profession on Utilization of Prescribed Eyeglasses}

The result of independent t-test of the influence of profession on the utilization of prescribed eyeglasses in Table 13 revealed significant influence of profession on the utilization of the prescribed eyeglasses; since the tcal of 3.19 was greater the t- critical of 1.96 as reflected in that table. This may have related to the fact that people of certain professions that have higher involvement in near-work activities have greater tendency to develop 
refractive errors that may require greater use of prescribed eyeglasses. Moreover, people of certain professions and occupations may need to have excellent vision than others to be able to function effectively in carrying out their duties. Among the staff of tertiary institutions, the academics have higher tendency to study continuously, make use of computers in their lecture preparations as well as much reading and marking of the students' scripts. Therefore, they have greater tendency to develop refractive errors that require greater use of prescribed eyeglasses than most of the administrative and technical staff, especially those that aren't highly educated. Since it is always an indispensable requirement for all academic staff to posses Ph.D degree as their mandatory qualifications; they are always highly educated personnel than some of the administrative/technical counterparts who have no such mandatory requirement. The longer years of studies to have the mandatory $\mathrm{Ph}$.D qualification may contribute to make most of the academics to develop refractive errors that require greater utilization of prescribed eyeglasses.

The finding of significant influence of profession on the utilization of prescribed eyeglasses in this study is in agreement with that of Wagner and Rein (2013) who had earlier obtained a higher degree of self reported limited abilities to read or deal with small prints in certain professions and occupational groups, requiring greater utilization and timely change of prescribed eyeglasses than other workers in other occupations. Furthermore, LaGrow and Daye (2005) identified barrier to certain employment based on individuals' visual disabilities due refractive errors without appropriate corrective measures. The authors confirmed that certain employment and professional duties required greater attention to visual health status, demanding greater utilization of prescribed eyeglasses or adaptation to other options of treatment in order to perform well in such occupations.

\section{The Influence of Years of Service on the Utilization of Prescribed Eyeglasses}

The result of one-way analysis of variance of the influence of years of service on utilization of prescribed eyeglasses in Table 14 yielded statistically significant influence of the years of service on utilization of prescribed eyeglasses. The finding was in consonance with that of Daun (2015) who carried out a study in the University of Alabama, at Birmingham School of Optometry to examine the relationship between the years of service and the vision of the computer workers and their productivity which had yielded positive association of the year of service of the computers workers to have been associated with computer vision syndrome. The author explained that workers with longer years of service had greater need of eye care services than newly employed ones and therefore, advised all employers to provide computer eye-wears and prescribed eyeglasses as need arises to workers, especially those of longer years of service for better productivity.

Similarly, Heiting (2015) recommended regular eye-checks and provision of eye-wears that can counter the adverse effect of computer use over the years to those that worked with computers over a long period of time. This therefore implied that those of longer years of computer use have greater eye risks and therefore required greater use of appropriate treatment option such as adequate use of prescribed eyeglasses. Ellahi, Khall and Akram (2011) reported apparent health disorders associated with longer years of service, stating categorically: that people who used computers and other computerized equipment to work about 25 to 30 years are more prone to have computer vision syndrome and muscular-skeletal disorders than others with fewer years of computer use.

It was therefore very clear that those of longer years of service need greater eye care services, such as the provision of prescribed eyeglasses than others with fewer years of service. Since most of the senior staff of tertiary institutions are using of computers in carrying out their duties. The increase in the years of computer use and commitment in all other aspects of their duties will demand greater use of prescribed eyeglasses and other eyecare services to ensure better eye-health status.

\section{The Influence of Income Status on the Utilization of Prescribed Eyeglasses}

The result of one-way analysis of variance of the influence of income status on the utilization of prescribed eyeglasses in Table 15 yielded statistically significant influence of income status on the utilization of prescribed eyeglasses among staff of tertiary institutions in Akwa Ibom State. The statistically significant influence of income status was obtained by a higher calculated F-value (F-cal) of 15.43, which was greater than the critical table F-value of 2.38 at .05level of significance, at 4 and 877 degrees of freedom. The utilization of eyeglasses and indeed every other aspect of healthcare services and the general health seeking behaviour of individuals and families in any population depend very much on their socio-economic status, which at all times include income status, level of education and environmental indices such as the availability of the healthcare services The good monthly incomes must have greatly contributed to their willingness and capability to pay for the prescribed eyeglasses as such need arises. 
The statistical significant influence of income status on the utilization of prescribed eyeglasses obtained in this study was similar to that of Wagner and Rein (2013) who had earlier obtained significant influence of income status on the utilization of eye care services and had reported better rate eye-care services utilization among people of higher income status in the United States. Similarly, Resnikoff et al (2008) submitted that uncorrected refractive errors were more prominent among people of poor income status of developing countries, emphasizing that poor income status was one of the major reason for the inadequate utilization of prescribed eyeglasses by people with viable refractive errors in all parts of the world, especially the developing countries. This goes in consonance with assertion of WHO (2003), which acknowledged that income status impact positive influence on utilization of healthcare services in every part of the world.

In the same perspective, Berkman and Kawachi (2000) acknowledged that better utilization of any aspect of health-care services depends on the socio-economic status of the people, emphasizing the fact that the majority of people from the developed or even the undeveloped parts of the world would appreciate and utilize essential health services, provided they have adequate finances to pay for such services. Lan and Boateng (2002) reported that poor income status was one of the major problems that hindered adequate utilization of prescribed eyeglasses as well as other aspect of eye-care services in Zambia. The authors reported that most of the rural Zambians believed that eyeglasses should be provided free to the people, emphasizing that most of the rural Zambians prefer free outreach programmes than going to eye hospital and clinic to test their eyes for whatever treatment and services. The authors concluded that the root causes of these behaviours came from poor socio-economic status of the people and wrong beliefs.

\section{The Influence of Age of onset (of vision impairment) on the Utilization of Prescribed Eyeglasses}

The result of one way analysis of variance (ANOVA) of the scores of the utilization of prescribed eyeglasses among staff of tertiary institution in Akwa Ibom State based on the age of onset (of their vision impairments) in Table 16 yielded statistically significant influence; since the F-cal of 5.70 was greater than the Fcritical of 2.61 at .05 level of significance, 3 and 878 degrees of freedom. The age at onset of individuals' vision impairment due to refractive errors and the outstanding activities of such periods of their lives have great influence to the health-seeking behaviours of such individuals, with special regards to the utilization of prescribed eyeglasses. The result of the present study indicated that the respondents who had vision impairments from childhood, young adulthood and those whose vision problem started at middle age were more influenced to make use of prescribed eyeglasses than others.

The findings of statistically significant influence of age of onset of individuals vision impairment on the utilization of prescribed eyeglasses is in agreement with the study of Leo and Young (2013), who through his evidence-based update programme of intervention for refractive errors (myopia) had advocated earlier treatment following the onset of vision impairment. Leo and Young recommended that earlier commencement of treatment was able to produce relative beneficial effects to people vision problem. The authors explained that timely utilization of prescribed eyeglasses following an onset of visual impairment can bring about meaningful level of improvement in visual status of individuals with vision impairments. The present study obtained statistically significant influence of the age of onset on utilization of prescribed eyeglasses among staff of tertiary institutions in Akwa Ibom State. The researcher has therefore identified the age of onset as one the outstanding variables that influence the utilization of prescribed eyeglasses (in the very first time) to the best knowledge.

\section{The Influence of Attitudes of Staff toward the Utilization of Prescribed Eyeglasses}

The result of independent t-test analysis in Table 17 revealed statistical significant influence of staff attitudes toward the utilization of prescribed eyeglasses in tertiary institutions in Akwa Ibom State, Nigeria. Earlier in Table 8, a total of $686(77.78 \%)$ respondents manifested positive attitudes toward the utilization of prescribed eyeglasses with mean of 154.60 ; while the remaining 196 respondents $(22.22 \%)$ had negative attitudes and mean of 136.71. The statistical significant influence of attitude toward utilization of prescribed eyeglasses was obtained in the study through a higher score of t-cal of 38.65 greater than the t-critical of 1.96 at .05 level of significance and 880 degrees of freedom. Attitudes of people in any population have tendencies to influence the health seeking behaviours and therefore may enhance or impede health care services utilization, including the utilization of prescribed eyeglasses. Individual's attitude toward the use of prescribed eyeglasses may influence appropriate utilization of the articles. This is one of the reasons why the acquisition of the prescribed eyeglasses may not always imply adequate utilization in all circumstances.

The finding obtained in the present study is similar to that of Adeoti (2009), who had earlier obtained statistically significant influence of attitude of the people of Oshogbo in Osun State toward utilization of prescribed 
eyeglasses. The author had also observed series of poor and negative attitudes toward the use of prescribed eyeglasses that militate against adequate utilization of prescribed eyeglasses in Nigeria, to include: refusal to go for professional eye test and examination with the licensed eye-care specialist, purchase of non-professionally prescribed glasses from the roadside/open market as well as the uncivilized manner and behaviour of constant wearing and removal of the eyeglasses from the user's faces.

Ebeigbe et al (2013) also obtained similar finding of positive influence of attitude in their study among the undergraduates of the University of Benin in Edo State. The authors reported that majority of the undergraduates with viable refractive errors were fond of shying away from proper utilization of prescribed eyeglasses, adding that many of such undergraduate refuse to undergo eye-examination so that they will not be found out or be known as having poor vision. Similarly, Ayansiyi and Olatungi (2008) also obtained poor influence of attitudes leading to poor compliance of spectacle wear in adult population in the South-Western Nigeria. The authors remarked that most of the respondents who had even obtained the prescribed eyeglasses were not making adequate use of such eyeglasses because many regarded the eyeglasses as intrusions to their faces.

However, Khaudakar, Sudhan, Jain, Tripathy and Singh (2008) obtained a contrary result from high school students in India, saying that attitude was not the actual things that cause the spectacle non-use over there, specifying poor financial status of the parents to have constituted the major hindrances to adequate utilization of prescribed eyeglasses. Ayanniyi, Fadamiro, Adeyemi, Focorunsoand Uzukwu (2010) from their study in AdoEkiti of Western Nigeria also obtained similar result that indicated that negative attitudes were among the causes of inadequate utilization of prescribed eyeglasses. These authors however, concluded that the most outstanding obstacle against adequate use of eyeglasses was the confronting socio-economic characteristic of the people, whereby most of the respondents were not able to afford the dispensing cost of the prescribed eyeglasses. The authors acknowledged that majority of the people with viable vision problems will appreciate prescribed eyeglasses provided such eyeglasses are provided at affordable cost or free of financial charges.

\section{The Influence of Beliefs on the Utilization of Prescribed Eyeglasses}

The result of the independent t-test analysis of scores of the utilization of prescribed eyeglasses among staff of tertiary institutions in Akwa Ibom State based on beliefs in Table 18 yielded statistically significant influence of beliefs on utilization of prescribed eyeglasses by a higher t-cal of 2.36, greater than t-critical of 1.96 at .05 level of significance and 880 degrees of freedom. The result of table 9 had earlier revealed that $865(98.07 \%)$ of respondents held positive beliefs about the utilization of prescribed eyeglasses while only $17(1.93 \%)$ of the respondents had negative beliefs. The majority of the respondents having positive beliefs must have related to the fact that most of the senior staff of tertiary institutions in Akwa Ibom State are made up of people of higher socioeconomic group and enlightened cultural backgrounds with greater privileges and better exposures. Therefore, most of the staff with viable refractive errors were able to acquire and made use of prescribed eyeglasses as well as possessing positive beliefs about the use of such eyeglasses.

The finding of statistically significant influence of beliefs in the study was similar to that obtained by Ebeigbe et al (2013) who had earlier obtained statistically significant influence of beliefs on the utilization of prescribed among the undergraduate students of the University of Benin in Edo State of Nigeria. However, Ebeigbe et al reported that most of the respondents in their study with viable vision problems that required correction with prescribed eyeglasses did not avail themselves to such treatment because of wrong beliefs. According to these authors, many of those undergraduate students refused the use of the prescribed eyeglasses because they believed that the eyeglasses were going to make people, especially theirs colleagues to tease at them or regard them as unfortunate people with very poor eye-health status. Some of the female students with refractive errors held negative beliefs that such eyeglasses may hinder them from being attractive to possible suitors.

Similarly Adeoti (2009) also obtained significant influence of beliefs on utilization of prescribed eyeglasses, but submitted that unfounded beliefs had made many of the respondents to be afraid of giving prescribed eyeglasses to their children, even when they have vision problems that required prescribed eyeglasses. Such parents believed that eyeglasses were not meant for the children even when they had viable refractive errors that required treatment and correction with the prescribed eyeglasses. Nevertheless, the majority of the staff of tertiary institutions in Akwa Ibom State in the present study held positive beliefs about the use of prescribed eyeglasses, contrally to what were obtained by the previous authors. As stated above, a total of 865 respondents $(98.07 \%)$ held positive beliefs and enjoyed using their prescribed eyeglasses to improve their visual health status and occupational output. 


\section{Summary of the Study}

The study was carried to determine the influence of socio-demographic variables on utilization of prescribed eyeglasses among staff of tertiary institutions in Akwa Ibom State, Nigeria. Basically, the influence of age, gender, level of education, profession, years of service, income status, attitudes, beliefs and age of onset (of vision impairment) on the utilization of prescribed eyeglasses were examined. In pursuance of the objectives of the study, nine research questions were formulated and nine hypotheses stated to guide the study. Related literatures were reviewed to provide theoretical, conceptual and empirical framework for the study.

A descriptive survey design was adopted for the study. The researcher considered the design as the most appropriate because it enhanced collection of first hand information from a large population of the respondents in the natural settings (their respective tertiary institutions). The target population comprised specifically only staff that used prescribed eyeglasses out of the 4,498 senior staff of the nine approved tertiary institutions that had obtained official licenses from National Universities Commission and National Board of Technical Education respectively. A sample size of 900 respondents ( 20 percent of the entire staff of the nine tertiary institutions), but specifically those that used prescribed eyeglasses were selected for the study through stratified purposive sampling technique. A Researcher Developed Instrument titled "Socio-demographic Variables and Utilization of Prescribed Eyeglasses Questionnaire (SVUPEQ) with a reliability index of .83 was used for data collection. Data collected were analyzed using for Statistical Package for Social Sciences (SPSS) software. Mean, standard deviation and mean of items were used in answering the research questions while independent t-test and one-way analysis of variance (ANOVA) were used for test of hypotheses. All hypotheses were tested at .05 probability level of significance.

The finding based on the results of data analyses indicated that socio-demographic variable exerted statistically significant influence on the utilization of prescribed eyeglasses based on level of education, profession, years of service, income status, attitudes, beliefs and age of onset (of vision impairment), However, age and gender (two of the nine variables) had no significant influence on the utilization of prescribed eyeglasses.

\section{Conclusions}

Consequent upon the findings of the study, it is hereby concluded that level of education, profession, years of service, income status, attitude, beliefs and age of onset (of vision impairment), are the socio-demographic variables that influence the utilization of prescribed eyeglasses among staff of tertiary institutions in Akwa Ibom State, Nigeria.

It is also concluded that age and gender have no significant influence on the utilization of prescribed eyeglasses among staff of tertiary institutions in Akwa Ibom State, Nigeria.

\section{Recommendations}

1. Intensive eye-care and vision-health education campaign should be regularly organized to ensure the provision of adequate information to staff of tertiary institutions and the general public concerning the usefulness of adequate utilization of prescribed eyeglasses and other aspects of eye-care services.

2. Staff of tertiary institutions who uses prescribed eyeglasses or those who undertake any other ophthalmic treatment regimen should endeavour to go for regular check-up to ensure better outcome and excellent visual health status.

3. Free eye-care services, especially the provision of prescribed eyeglasses should be given to staff of lower income status to ensure sound eye-health status.

4. Staff of tertiary institutions and other people with any form of vision impairment should endeavour to consult registered eye-health professionals to ensure authentic eyecare and services based on their individual eye conditions.

5. Staff of tertiary institutions in Akwa Ibom State as well as other people with vision impairment that require the use of eyeglasses, including people with other eye problems should endeavour to go for regular checkup at least one time yearly for careful assessment of their conditions.

6. Tertiary institutions in Akwa Ibom State and beyond should endeavour to establish eye-health unit in their health centres/sick bay to provide primary and essential eye-care services to staff and students. 
7. The federal, state as well as private owners of tertiary institutions should endeavour to improve upon the salaries of their staff to enable them to attain to their health needs including acquisition of prescribed eyeglasses when need arises.

8. Staff of tertiary institutions who had served for more than twenty five years should be given incentive of free eye-care services especially those whose duties require much reading and frequent use of computers because longer years of services require greater eye-care services.

9. Special consideration and incentive for free eye-care should be given to staff with higher level of education, especially those with Ph.D. and those that had attended professorship for exposing their eyes during many years of studies to contribute to expansion and growth of knowledge.

\section{Limitations of the Study}

The study on "Socio-demographic Variables and Utilization of Prescribed Eyeglasses among Staff of Tertiary Institutions in Akwa Ibom State, Nigeria', was strictly limited to the scope of the study. Therefore, the generalizations and application of its findings cannot be extended beyond the utilization of prescribed eyeglasses to any other treatment option of vision impairment due to refractive errors. The findings of the present study may not be appropriately generalized to cover other aspects of eye-care services or other health care services in the state and beyond. Some suggestions are therefore given for further studies as below.

\section{Suggestions for Further Studies}

In view of the findings of this present study, the researcher hereby made the following suggestions for further studies:

1. Assessment of psychosocial aspect of refractive errors and effectiveness of health education in correcting stigmas related to the prescribed spectacle use among undergraduates students of University of Uyo, Akwa Ibom State.

2. Knowledge, beliefs and attitudes toward the use of prescribed eyeglasses among public secondary school teachers in Akwa Ibom State.

3. Assessment of knowledge of visual status and uptake of eye-care services among the postgraduate students of tertiary institutions in Akwa Ibom State.

\section{References}

Adams, V., and Awunor, N. (2014). Perception of factors affecting utilization of health services in a rural community in southern Nigeria. Journal of Biomedical Sciences, 13 (2), 117-124.

Adeoti, C. C. (2009). Beliefs and attitudes toward the uses of prescribed spectacles among the people of Osun State. Nigerian Journal of Clinical Practice, 12 (4), 361-369.

Akpan, E. U. (2015).The statistics of senior administrative/academic staff in Akwa Ibom State Polytechnic. Ikot Osurua: Akwa Ibom State Polytechnic. (Correspondence: 21st December 2015).

Akwa Ibom State Diary (2015). Akwa Ibom State Government Diary on political and cultural heritage. Uyo: Akwa Ibom State Government Press.

Ayansiyi, A., and Olatungi, F. (2008). Factors associated with non-compliance to spectacle wear in Nigeria. Asian Journal of Ophthalmology, 3, 86-94.

Ayanniyi, A, Fadamiro F, Adeyemi, F, Focorunso B., and Uzukwu, A. (2010). Common refractive errors among the Ekitis of South-Western Nigeria. Asian Journal of Ophthalmology, 2, 90-99.

Baker, R., Bazargan, M., Bazargan, H, S., and Calderon, A. (2005). Access to vision care in urban-low income population. Journal of Ophthalmic Epidemiology, 12 (1), 1-12.

Berkman, L, F., and Kawachi, I. (2000). Social Epidemiology. New Yok: Oxford University Press.

Calonge, N. (2013). Vision and learning for professionals and educators. Retrieved May 8th, 2015, from $\mathrm{http} / /$ :www.pavion-learningcentre.com.

Dandona, L., and Dandona R. (2006a). What is the global burden of visual impairment? British Medical Journal, 1, 6-10. 
Dandona, L., and Dandona, R. (2006b). Revision of visual impairment in the International Classification of Diseases. British Medical Journal, 1, 134-141.

Daun, K. (2015). The relationship between the vision of computer workers and their productivity in workplaces. Retrieved October 15th, 2016, from All About Vision Media @: :www.allaboutvision.com/cvs/productivity.htm.

Ebeigbe, F., Kior, F., and Okafor, L. I. (2013). Attitude of Nigerians undergraduate to spectacle wears. Ghana Medical Journal, 47 (2), 70-73.

Elensi, E. A. (2016). Senior staff statistics in Akwa Ibom State University (AKSU). Ikot Akpaden: Akwa Ibom State University (Correspondence: 12th January, 2016).

Ellahi, A., Khall, M. S., and Akram, F. (2011). Computer users at risk: Health disorders associated with longer years of computer use. Journal of Business Management and Economics, 2 (4), 171-182.

Essien, E. (2015). Statistics of academics and senior administrative/technical staff of Maritime academy. Oron: Maritime academy.

Ezelum, C., Razavi, H., Silvabramamian S., Gilbert C., Murthy G. V., Entekume, G., and Abubakar,T. (2011). Refractive errors in Nigerian's adult populations: Prevalence, type and spectacle cov erage. Investigative Ophthalmology and Visual Science Journal, 52, 5449-5456

Fletcher, A., Donoghue, M., Davavaran J., and Murugan (2009). Achieve Ophthalmology, 117 (10), 1393-1399.

George, A. (2012). Presbyopia; what it is, causes and risk factors. Health line publication, Retrieved May 21st 2015 from: http://www.healthline.com/health/presbyopiariskfactors

Goldschmidt, E., and Jacobsen, N. (2014). Genetic and environmental effect on myopia development and progression. The Scientific Journal of the Royal College of Ophthalmologist, 28 (2), 126-133.

Heiting, G. (2015). Workers Productivity and Computer Vision Syndrome. New York City: All About Vision Media Communication.

Holden, B. A., Fricke, T., and Naidoo, K. S. (2008). Global vision impairment due to uncorrected refractive errors and presbyopia. Achieve Ophthalmology, 126, 1731-1739.

Idu, F. K. and Udom, U. C. (2004). Prevalence of blindness due to refractive errors in Nigeria: Strategic Eye-care Services Development. WHO Publication. 97.61.

International Agency for Prevention of Blindness (IAPB) (2006). Vision 2020: The Right to Sight.: London. IAPB Publication.

Jin, Y. P., and Trope, G. E. (2011). Eye-care services utilization in Canada: Disparity in the public funded healthcare system. Canada Journal of Ophthalmology, 46 (2), 133-138.

Jones, P. B. (2013). Adult mental health disorder and their age at onset. The British Journal of Psychiatry, 202 (54), 112-119.

Khaudakar, H., Sudhan J., Jain, B., Tripathy, H., and Singh, T. (2008). Determinants of compliance to spectacle wear among the high school students in central India. Indian Journal of Ophthalmology, 3, 86-94.

La-Grow, S. J., and Daye, D. (2005). Barriers to employment identified by the blind and vision impaired persons in New Zealand. Social Policy Journal of New Zealand, 26, 36-47.

Lan, Y., and Boateng, W. (2002). An organization of outreach eye-care programme in Zambia. Journal of Community Eye-health, 15 (41), 13-24.

Leo, S., and Young, T. (2013). An evidence-based update of myopia and its intervention to retard its progression. Journal of American Association of Paediatric Ophthalmologist and Strabismus, 15 (2), 181-189.

Liping, L., Jasmine, L., and Yaugu, L. (2010). Attitude of students, parents and teachers toward the use of glasses in rural China. Archieve. Ophthalmology, 128, 759-765.

Megbalayin, E. O. (2013). Barrier to uptake of prescribed refractive spectacles among Nigerian students. International Research Journal of Basic and Clinical Studies, 1 (5), 71-77.

Morse, K. (2013). Factors that influence utilization of health services. Retrieved December 25th, 2014, from www.enotes.corn/homework help/factors-that influence-utilization 444585.

National Population Commision (NPC) (2013). An estimated population of Akwa Ibom State of Nigeria. Abuja: N. P. C. Publication.

Ndiyo, N. A. (2005). Fundamentals of research in behavioural sciences and humanities. Calabar: Wusen Publishers.

Nirmalan, P. K., Krishnaiah, S., and Shamannah, B. R. (2006). A population-based assessment of presbyopia in the state of Anthra Pradesh. The Anthra Pradesh eyeglasses study. Investigation Ophthalmology and Visual Science, 6, 201-213.

Nishah, A. (2014). People with higher level of education have more tendencies to have myopia. Journal of Ophthalmology, 6 (2), 243-249. 
Oladipo, J. A. (2014). Utilization of healthcare services in rural and urban areas of Kwara State: A determinant factor in planning and managing healthcare delivery system. Journal of African Health Science, 14 (2), 322-333.

Resnikoff, S., Pascolini, D., Marrioti S. P., and Pokharel G. (2008). Global magnitudes of visual impairment caused by uncorrected refractive errors. Bulletin of the World Health Organization, 86, 63-70.

Toit, R., Ramke, J, Naduvilath, T., and Brein, G. (2006). Awareness and use of eye-care services in Figi. Ophthalmic Epidemiology, 13 (5), 309-320.

University of Uyo (2015). Annual report of 2012/2013 acedemi year. Uyo: University of Uyo/Reapzimedia puplication.

Utiam, F. U. (2015). The statistic of senior administrative/academic staff in Akwa Ibom State College of Education. Afaha Nsit: Akwa Ibom State College of Education. (Correspondence: 21st December, 2015).

Vision Spring (2007). Better vision for the poor. Sanford: Sanford's Vision Project/Vision Spring Bulletin.

Wagner, R. D., and Rein D. B. (2013). Attribute associated with eye-care utilization in the United State of America: A meta-analysis. Ophthalmology, 120 (7), 1497-1501.

Waldron, P. (2014). Why they need eyeglasses? People with higher level of education are more likely to be near sighted. Retrieved June 23rd, 2015, from: www.insidescience.why.nerds.need.glass $\underline{\mathrm{es} / 1766 .}$

WHO (2003). Impact of socio-economic status on people's health and illness. Geneva: World Health Organization Publication.

WHO (2008). Global magnitude of vision impairment due to uncorrected refractive errors. Geneva: Bulletin of the World Health Organization.

WHO (2013). What is a refractive error? Geneva: World Health Organization Publication. Accessed June $25^{\text {th }}$, 2016, from: www.who int.

Yanoff, M., and Duker, J. S. (2008). Ophthalmology (3rd ed). Edinburgh: Mosby Publishing Company. 